\title{
An astrocyte-dependent mechanism for neuronal rhythmogenesis.
}

\author{
Philippe Morquette ${ }^{1}$, Dorly Verdier ${ }^{1}$, Aklesso Kadala ${ }^{1}$, James Féthière ${ }^{2}$, \\ Antony G. Philippe ${ }^{3,4}$, Richard Robitaille ${ }^{2}$, Arlette Kolta ${ }^{1,5 *}$
}

\section{Affiliations:}

${ }^{1}$ Département de Neurosciences and Groupe de Recherche sur le système Nerveux Central, Université de Montréal, Montréal, Québec, Canada.

${ }^{2}$ Faculté de Pharmacie, Université de Montréal, Montréal, Québec, Canada.

${ }^{3}$ Faculté des Sciences du Sport, Université Montpellier 1, Montpellier, France

${ }^{4}$ INRA, UMR866 Dynamique Musculaire Et Métabolisme, Montpellier, France

${ }^{5}$ Faculté de Médecine Dentaire and FRQS Network for oral and bone health research, Université de Montréal, Montréal, Québec, Canada.

*Correspondence to: Arlette Kolta, Arlette.kolta@umontreal.ca 


\section{ABSTRACT:}

Communication between neurons rests on their capacity to change their firing pattern to encode different messages. For several vital functions, such as respiration and mastication, neurons need to generate a rhythmic firing pattern. Here we show in the rat trigeminal sensori-motor circuit for mastication that this ability depends on regulation of the extracellular $\mathrm{Ca}^{2+}$ concentration $\left(\left[\mathrm{Ca}^{2+}\right]_{\mathrm{e}}\right)$ by astrocytes. In this circuit, astrocytes respond to sensory stimuli that induce neuronal rhythmic activity, and their blockade with a $\mathrm{Ca}^{2+}$ chelator prevents neurons from generating a rhythmic bursting pattern. This ability is restored by adding $\mathrm{S} 100 \beta$, an astrocytic $\mathrm{Ca}^{2+}$-binding protein, to the extracellular space, while application of an anti-S100 $\beta$ antibody prevents generation of rhythmic activity. These results indicate that astrocytes regulate a fundamental neuronal property: the capacity to change firing pattern. These findings may have broad implications for many other neural networks whose functions depend on the generation of rhythmic activity.

\section{INTRODUCTION}

The pattern of activity that emerges from a neuronal network defines the essence of its function. Many fundamental nervous functions including attention, learning and memory and control of sleep/wake cycle result from rhythmic or oscillatory activities in neuronal networks. Obvious examples of such functions are rhythmic movements such as walking, breathing and chewing which are generated by networks referred to as Central Pattern Generators (CPGs) ${ }^{1-3}$. These networks generate a rhythmic motor activity that is constantly adjusted by sensory feedback to produce a movement pattern that is adapted to the prevailing conditions. Despite intense research in this field, the exact mechanisms underlying generation of this rhythmic activity and its adaptation by sensory inputs remain elusive. Some studies point to the role of intrinsic pacemaker properties, while others emphasize the role of synaptic connections to generate rhythmic firing ${ }^{4}$. In a few models, rhythmic network properties emerge from the combination of intrinsic properties and synaptic connections, but the mechanism underlying their interaction is ill-defined ${ }^{5}$. In most instances, the potential contribution of astrocytes, the most abundant type of cells in the brain, is largely ignored. Only in respiration has it been shown that astrocytes play a significant role by detecting $\mathrm{pH}$ changes in the blood and modulating neuronal firing in return ${ }^{6,7}$.

Several ionic conductances endow neurons with rhythmogenic abilities. $I_{\mathrm{NaP}}$, a voltage-dependent sodium persistent current, is one such conductance which has been shown to underlie rhythmogenesis in the cortex, the hippocampus, and several brainstem and spinal CPG systems. Rhythmogenic neurons of the trigeminal circuit involved in mastication and of the spinal locomotor CPG have $I_{\mathrm{NaP}}$-mediated rhythmic bursting properties that are enhanced when the extracellular $\mathrm{Ca}^{2+}$ concentration $\left(\left[\mathrm{Ca}^{2+}\right]_{\mathrm{e}}\right)$ diminishes ${ }^{8,9}$. Here we propose that this $\mathrm{Ca}^{2+}$ dependency forms the basis of the mechanism that enables synaptic inputs of sensory afferents to interact with intrinsic bursting properties and determines the neuronal ability to change firing pattern. We show that, in the dorsal part of the trigeminal main sensory nucleus (NVsnpr) where rhythmogenic neurons are found, stimulation of sensory fibers which project to the nucleus activate astrocytes. In turn, astrocytes regulate the external $\mathrm{Ca}^{2+}$ to trigger bursting by releasing a $\mathrm{Ca}^{2+}$ binding protein, $\mathrm{S} 100 \beta$. Specific inactivation of astrocytes prevents neuronal bursting which can only be rescued by addition of $S 100 \beta$ and inversely; bursting cannot be produced when $\mathrm{S} 100 \beta$ is blocked. These results will help understand the mechanisms leading to rhythmic firing and may have widespread implications for normal functions relying on rhythmogenesis as well as abnormal rhythmic firing observed in several pathologies such as Parkinson disease or epilepsy where astrocytes are known to be involved.

\section{RESULTS}

Burst-inducing stimuli decrease external Calcium

We showed, in previous work, that rhythmic bursting could be elicited in NVsnpr neurons by artificially reducing the $\mathrm{Ca}^{2+}$ concentration of the perfusing medium ${ }^{9}$. Decreases of $\left[\mathrm{Ca}^{2+}\right]_{\mathrm{e}}$ have been reported to occur during intense or sustained neuronal activity ${ }^{10}$ or during pharmacologically-induced locomotor-like activities in isolated neonatal rodent spinal cords ${ }^{11}$, but it is unknown whether they occur in the trigeminal system and if they can be elicited by more "physiological" stimuli. We first tested the effects of electrical stimulation of the trigeminal tract on $\left[\mathrm{Ca}^{2+}\right]_{e}$ and on neuronal firing. The trigeminal tract contains fibers of sensory afferents that project to NVsnpr. Ion-sensitive electrodes were used to monitor $\left[\mathrm{Ca}^{2+}\right]_{\mathrm{e}}$ following repetitive stimulation of the tract at $40 \mathrm{~Hz}$, a frequency close to the sensory afferents natural firing frequency during mastication ${ }^{12}$. To avoid possible washout of small external $\mathrm{Ca}^{2+}$ changes that could result from the rapid perfusion in a submerged preparation chamber, we conducted these experiments in a Haas type interface 
chamber where preparations were maintained at the interface between a warm humidified atmosphere of $\mathrm{O}_{2} / \mathrm{CO}_{2}$ and a perfusing artificial cerebrospinal fluid (aCSF) containing $1.6 \mathrm{mM} \mathrm{Ca}^{2+}$ (Fig. 1a). However, only extracellular recordings can be conducted in this condition. In $14 / 22$ cells, repetitive stimulation of the trigeminal tract produced long lasting decreases of $\left[\mathrm{Ca}^{2+}\right]_{\mathrm{e}}$ in dorsal NVsnpr (average drop: $1.1 \pm 0.1 \mathrm{mM} ; \geq$ $30 \mathrm{~min}$; Fig. 1b), while in the remaining 8 cases, no changes could be detected. In 5 of those 14 cases, the $\mathrm{Ca}^{2+}$ drop was of smaller amplitude $(0.7 \pm 0.1 \mathrm{mM})$ and no changes were observed on firing patterns of adjacent cells recorded. However, in the 9 remaining cases, $\left[\mathrm{Ca}^{2+}\right]_{\mathrm{e}}$ dropped beneath $0.4 \mathrm{mM}$ (average drop of $1.3 \pm 0.1 \mathrm{mM}$ ) and in all of these 9 cases, the firing pattern of neurons recorded extracellularly near the $\mathrm{Ca}^{2+}$ sensitive electrode, changed from tonic to rhythmic bursting (Fig. 1c-d). Firing patterns considered as rhythmic bursting and as tonic firing are illustrated in Supplementary Fig. 1 and the criteria used for their distinction are described in material and methods. Bursting occurred at an average frequency of $8.56 \mathrm{~Hz} \pm 1.02$ (Supplementary Table 1), well within the frequency range of EMG bursts observed in the jaw muscles of freely chewing rats $(5-11 \mathrm{~Hz}$, with a mean of $8.5 \mathrm{~Hz})^{13}$.

We then sought a robust stimulus to induce bursting and $\left[\mathrm{Ca}^{2+}\right]_{\mathrm{e}}$ decreases in submerged preparations, in order to conduct whole-cell recordings and $\mathrm{Ca}^{2+}$-imaging. In a previous study we had shown that rhythmic bursting elicited in NVsnpr neurons following stimulation of sensory afferents was blocked by an antagonist of NMDA receptors, APV, suggesting that these receptors are involved in burst induction ${ }^{14}$. Hence, we assessed if $\left[\mathrm{Ca}^{2+}\right]_{\mathrm{e}}$ and neuronal firing pattern were altered by local applications of NMDA (1-2 mM) in both interface and submerged slice preparations. In interface preparations ( $n=12$ cells in 12 slices from 12 animals), local NMDA applications elicited rhythmic bursting at frequencies close to rhythmic bursting elicited by stimulation of sensory afferents (Supplementary Table 1). In submerged preparations, similar NMDA applications produced $\left[\mathrm{Ca}^{2+}\right]_{\mathrm{e}}$ decreases $(0.89 \pm 0.11 \mathrm{mM}$; $n=8$ ) (Fig. 1e) of shorter duration than those elicited by stimulation of sensory fibers in interface chamber (23.69 $\pm 4.58 \mathrm{~s})$. When applied near a neuron held at its resting membrane potential (RMP), NMDA caused a long lasting depolarization and induced firing, but the firing pattern remained tonic ( $n=5 / 5$ at $2 \mathrm{mM}$ and $3 / 3$ at $1 \mathrm{mM}$ ) (Fig. 1f). Rhythmic bursting (Supplementary Table 1) occurred only if the neurons were hyperpolarized prior to NMDA application ( $n=37$ at $2 \mathrm{mM}, n=54$ at $1 \mathrm{mM}$ in slices from 74 animals) (Fig. 1f ) and showed the same voltage-

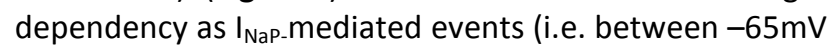
and $-50 \mathrm{mV})^{15}$ (Supplementary Table 1). Further, this NMDA-induced bursting was abolished by two $\mathrm{I}_{\mathrm{NaP}}$ blockers (TTX, $1 \mu \mathrm{M} ; n=5$ cells in 5 slices from 5 animals; not shown and riluzole $20 \mu \mathrm{M} ; n=3$; Fig. 1g).

\section{$\mathrm{I}_{\mathrm{NaP}}$-mediated bursting is modulated by $\left[\mathrm{Ca}^{2+}\right]_{\mathrm{e}}$ but not $\left[\mathrm{Ca}^{2+}\right]_{\mathrm{i}}$}

The above results suggest that bursting is associated with $\left[\mathrm{Ca}^{2+}\right]_{\mathrm{e}}$ decreases, but do not discriminate whether it is the extracellular $\left[\mathrm{Ca}^{2+}\right]$ or the potential subsequent fluctuation of intracellular $\left[\mathrm{Ca}^{2+}\right]$ that promotes bursting. Under control conditions, when using a physiological $\left[\mathrm{Ca}^{2+}\right]_{\mathrm{e}}(1.6 \mathrm{mM})^{16}$ in the perfusing medium, most neurons had a tonic firing pattern when activated with intracellular current injections or when firing spontaneously. Their firing pattern switched to rhythmic bursting when the perfusing medium was changed to a $\mathrm{Ca}^{2+}$-free aCSF ( $n=12$; Fig. $2 \mathrm{a}$ and Table 1 ) even though no changes were observed in their RMP $(-53 \pm 1 \mathrm{mV}$ in controls vs $-54 \pm 2 \mathrm{mV}$ in $\mathrm{Ca}^{2+}$-free aCSF; paired $t$-test; $P$ $=0.364 ; n=12)$ and in their input resistance $(276 \pm 55$ $\mathrm{M} \Omega$ in controls vs $267 \pm 51 \mathrm{M} \Omega$ in $\mathrm{Ca}^{2+}$-free aCSF; paired $t$-test; $P=0.81 ; n=10)$. Even more confined $\mathrm{Ca}^{2+}$ reductions of shorter duration induced by local extracellular application of the $\mathrm{Ca}^{2+}$ chelator BAPTA (5-35 $\mathrm{mM}$ ) near the recorded neurons induced rhythmic bursting ( $n=13 / 13$; Fig. $\mathbf{2 b}$ ). In contrast, depletion of neuronal intracellular $\mathrm{Ca}^{2+}$ by addition of BAPTA (10-35 $\mathrm{mM}$ ) to the solution used in the recording electrode did not induce bursting in neurons firing tonically under physiological $\left[\mathrm{Ca}^{2+}\right]_{\mathrm{e}}(n=11)$ (Fig. 2c) and did not prevent NMDA-induced bursting $(n=3 / 3)$ (Fig. 2c). As with NMDA, bursts induced by local applications of extracellular BAPTA were $I_{\mathrm{NaP}}$-dependent since they were abolished by riluzole ( $n=5 / 6$; Fig. $2 d$ ). 
Sensory fiber stimulation in the interface configuration

a Single unit

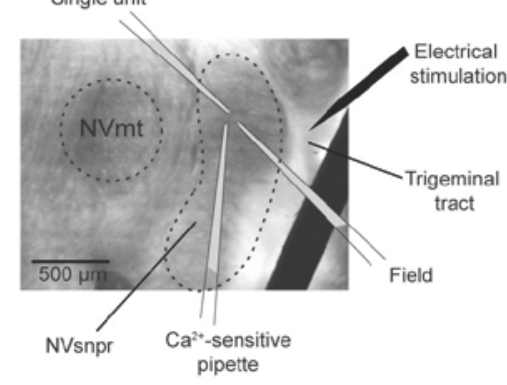

C

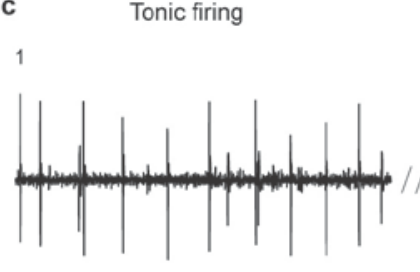

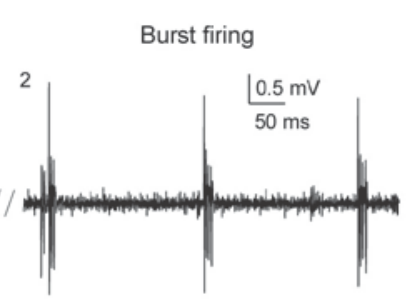

b

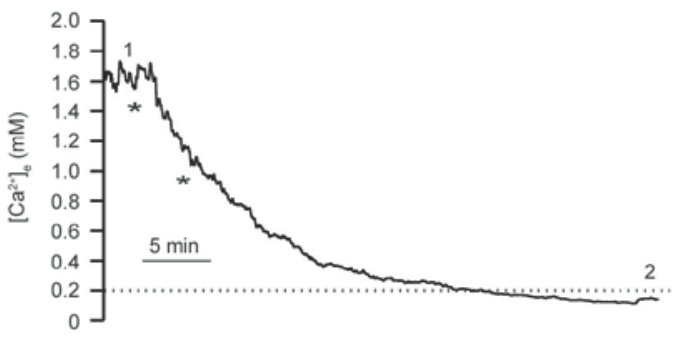

d

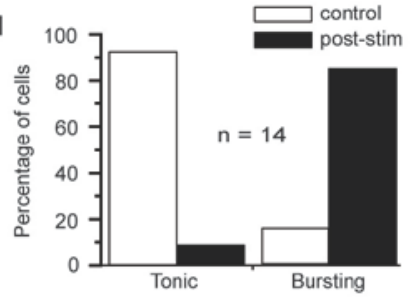

NMDA application in the submerged configuration
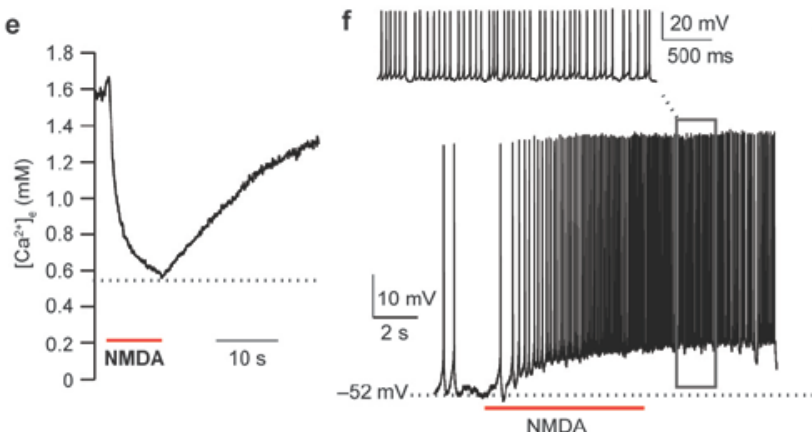

g
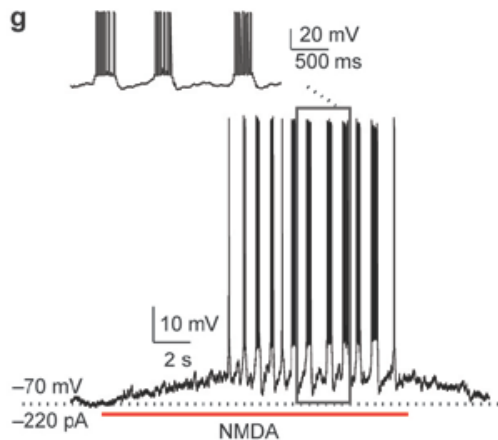

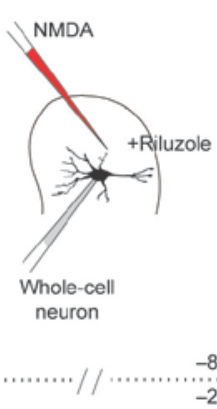

$-80 \mathrm{mV}$
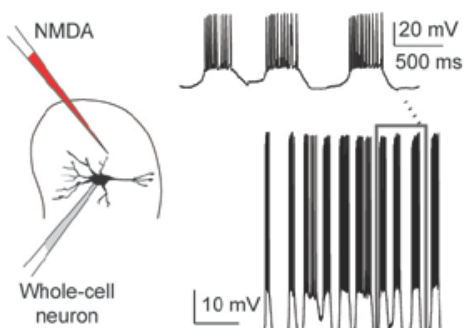

$\mathrm{mV}$

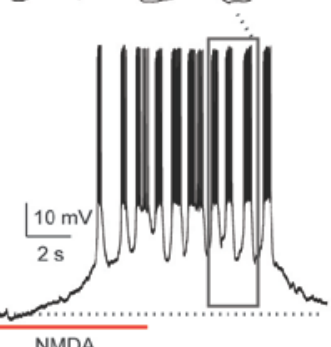

Figure 1: Sensory fibers stimulation and local NMDA application lead to $\left[\mathrm{Ca}^{2+}\right]_{\mathrm{e}}$ decreases and $\mathrm{I}_{\mathrm{NaP}}$ dependant neuronal bursting. (a) Stimulating and recording electrodes arrangement used in the interface chamber superimposed on a brainstem slice photomicrograph. NVmt $=$ Trigeminal motor nucleus, NVsnpr $=$ Trigeminal main sensory nucleus. (b) Electrical stimulation $\left({ }^{*} 1 \mathrm{~s}\right.$ trains at $\left.40 \mathrm{~Hz}\right)$ of sensory fibers in the trigeminal tract, caused a long-lasting decrease in $\left[\mathrm{Ca}^{2+}\right]_{e}$ ( $n=14$ to 22 recording locations in 18 slices from 14 rats). (c) Example of a neuron with a firing pattern that was tonic prior to stimulation (1) and became rhythmically bursting (2) when [Ca $\left.{ }^{2+}\right]$ dropped under $0.3 \mathrm{mM}$ (dotted line in b). (d) Firing pattern prevalence before and after stimulation (post-stim) of the tract (See also Supplementary Fig. 1). (e) In submerged preparations, local application of NMDA $(1 \mathrm{mM})$ also caused a $\left[\mathrm{Ca}^{2+}\right]$ decrease $(\mathrm{n}=8$ applications in 2 slices from 2 animals. (f) Left: At resting membrane potential, such applications produced a large depolarisation and an increase in firing frequency, but no bursting (see inset) (1 mM: $\mathrm{n}=5$ cells in 3 slices from 3 rats; $2 \mathrm{mM} ; \mathrm{n}=3$ cells in 3 slices from 1 rat). Right: Rhythmic bursting (see inset) was induced if the neuron was hyperpolarized by current injection prior to the application. (g) Left: Rhythmic bursting induced by local application of NMDA (1 mM) is prevented when a blocker of $\mathrm{I}_{\mathrm{NaP}}$ channels, riluzole $(20 \mu \mathrm{M})$ is added to the bath (Right). In this condition, NMDA no longer induced bursting, but was still strongly depolarizing and excitatory ( $n=3$ cells in 3 slices from 3 animals). 
a Control

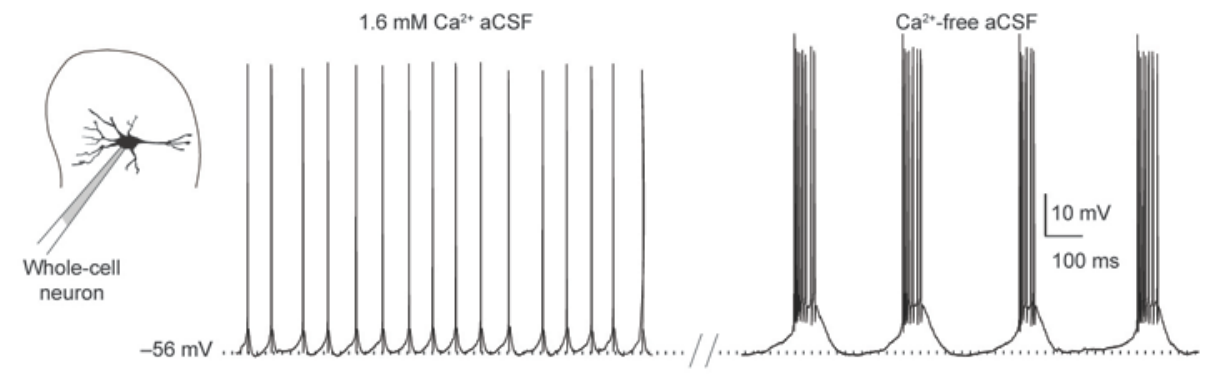

b Extracellular BAPTA

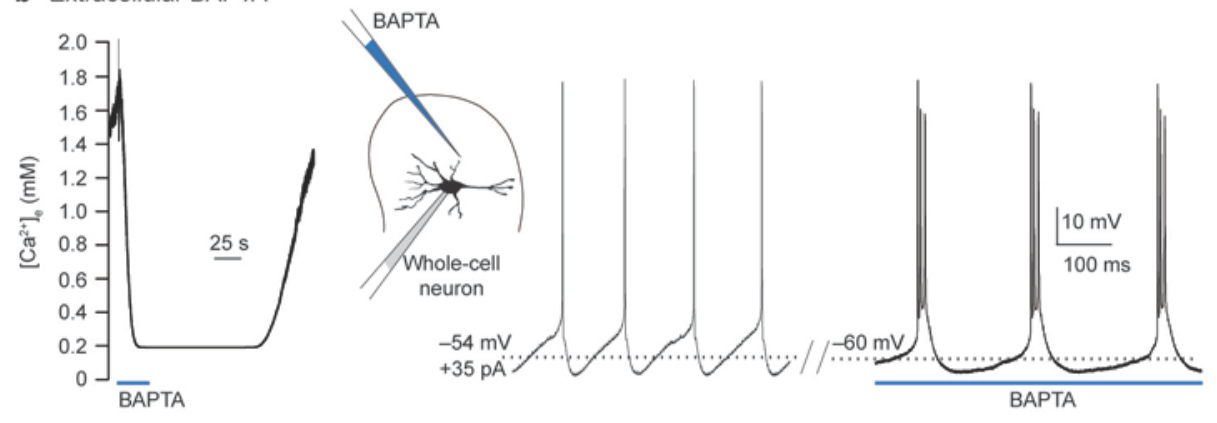

c Intracellular BAPTA

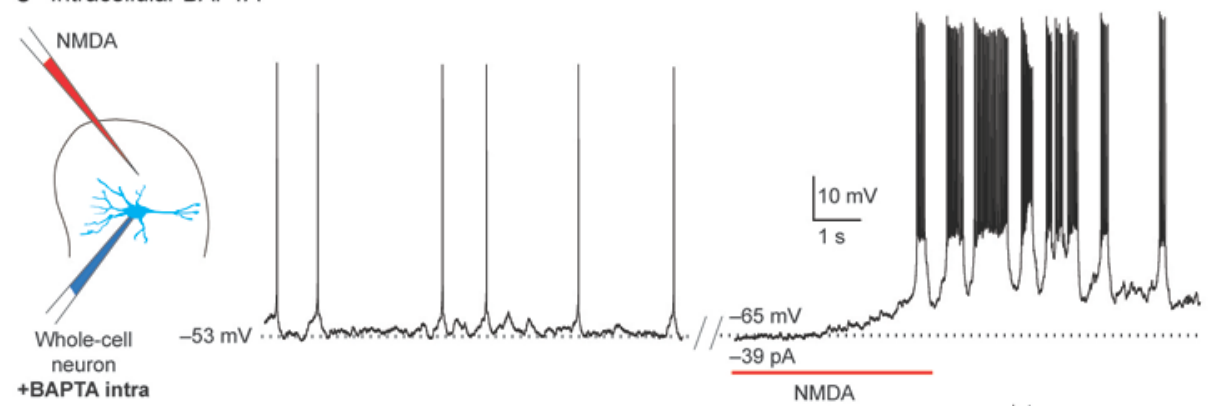

+BAPTA intra

d

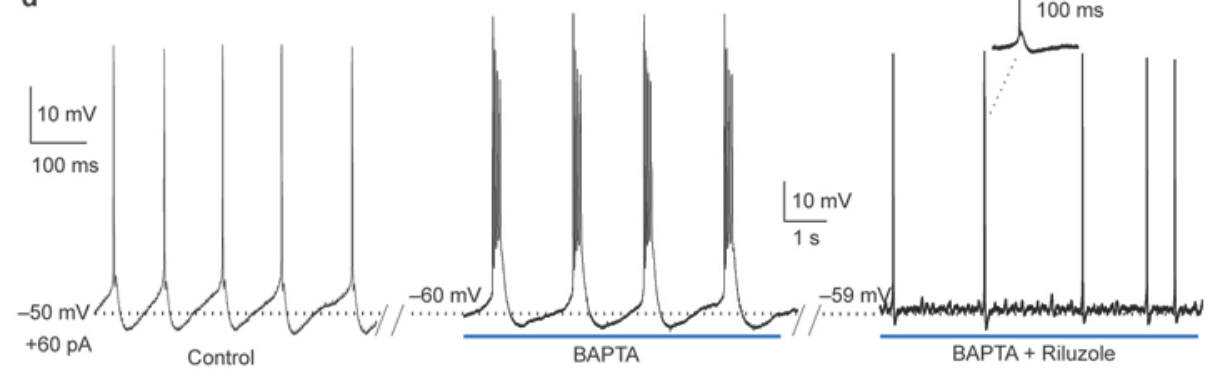

Figure 2: Reduction of extracellular $\mathrm{Ca}^{2+}$ leads to $\mathrm{I}_{\mathrm{NaP}}$ dependant bursting independently from effects on intracellular $\mathrm{Ca}^{2+}$. (a) The tonic firing pattern of NVsnpr neurons recorded under physiological $(1.6 \mathrm{mM})\left[\mathrm{Ca}^{2+}\right]_{\mathrm{e}}$ (left) switches to burst firing when the perfusing medium is replaced by a $\mathrm{Ca}^{2+}$-free medium ( $n=12$ cells in 10 slices from 10 animals. (b) Local extracellular application of BAPTA (10 mM; submerged preparation) produced a large but transient decrease of $\left[\mathrm{Ca}^{2+}\right]_{e}$ (left) and induced rhythmic bursting (right) in an adjacent NVsnpr neuron which was firing tonically prior to the application (middle) ( $n=13$ cells in 9 slices from 9 animals). (c) The switch is not due to lack of intracellular $\mathrm{Ca}^{2+}$ since chelation of neuronal intracellular $\mathrm{Ca}^{2+}$ by adding BAPTA $(35 \mathrm{mM})$ to the recording pipette solution did not induce rhythmic bursting in a neuron firing tonically under physiological $\left[\mathrm{Ca}^{2+}\right]_{e}(1.6 \mathrm{mM})$ (left, $\mathrm{n}=11$ cells in 11 slices from 7 animals) and did not prevent NMDA-induced recurrent bursting in the same neuron (right, $n=3$ cells in 3 slices from 3 animals). (d) Local extracellular application of BAPTA (10 mM) near a tonically firing NVsnpr neuron (left) induced rhythmic bursting (middle) under control conditions, but not in presence of riluzole $(20 \mu \mathrm{M})$ in the bath. In that case (right), BAPTA had an effect on the spike after hyperpolarization, but little effect on the firing pattern ( $n=5$ of 6 cells in 6 slices from 5 rats). 
Low $\left[\mathrm{Ca}^{2+}\right]_{\mathrm{e}}$ has been reported to enhance $\mathrm{I}_{\mathrm{NaP}}{ }^{9,11,17,18}$. To ensure that this is the case here, we performed a series of voltage clamp experiments in a modified aCSF (see material and methods) to pharmacologically block $\mathrm{Ca}^{2+}$ and $\mathrm{K}^{+}$conductances and isolate $\mathrm{Na}^{+}$currents. A slow voltage $\operatorname{ramp}(18 \mathrm{mV} / \mathrm{s}, 5 \mathrm{~s})$ was used to activate $I_{\mathrm{NaP}}$ without activating fast sodium currents. In 11 dorsal NVsnpr neurons tested, the slow voltage-clamp command produced an inward sodium current (Supplementary Fig. 2a). Local application of extracellular BAPTA (10 $\mathrm{mM})$ during the ramp protocol ( $n$ $=6$ ) increased the peak of this inward current (Supplementary Fig. 2b) by $58 \pm 13 \%$. Peak currents were obtained at $-44.7 \pm 1.3 \mathrm{mV}$ under control conditions and at $-48.5 \pm 1.7 \mathrm{mV}$ with BAPTA; a shift of $8 \%$. This inward current was blocked with bath application of riluzole (20 $\mu \mathrm{M} ; n=4$ cells in 4 slices from 3 rats $)$ or TTX ( $1-2 \mu \mathrm{M} ; n=$ 2 cells in 2 slices from 1 animal). Subtraction of the trace obtained under riluzole or TTX from the traces obtained under control conditions or BAPTA allowed isolation of the $\mathrm{I}_{\mathrm{NaP}}$ current (Supplementary Fig. 2c). The characteristics of this isolated $I_{\mathrm{NaP}}$ current were obtained with the fitting of a single Boltzmann function to the normalised (to $g_{\max }$ ) conductance-voltage data (Supplementary Fig. 2d)

Taken together, these results strongly suggest that extracellular decrease of $\left[\mathrm{Ca}^{2+}\right]$ promotes bursting and enhances $I_{\mathrm{NaP}}$ currents.

$A$ recent report showed that decreasing $\left[\mathrm{Ca}^{2+}\right]_{\mathrm{e}}$ alters neuronal discharge through an astrocytic ATPdependent mechanism ${ }^{19}$. To verify whether bursting induced by $\mathrm{Ca}^{2+}$ decreases somehow involved ATP release and purinergic receptors, we assessed the effects of bath applied Suramine (50 $\mu \mathrm{M}$, for more than 1 hour), a large spectrum antagonist of purinergic receptors and found no effects on bursting induced by extracellular BAPTA (10 mM) applications in 5/5 cells (Supplementary Fig. 3).

\section{Astrocytes respond to burst-inducing stimuli}

Since regulation of extracellular ions is a key mechanism by which astrocytes impact on neuronal functions ${ }^{20}$, we hypothesized that astrocytes may play a role in neuronal bursting by regulating $\left[\mathrm{Ca}^{2+}\right]_{\mathrm{e}}$. In this case, they should respond to the two stimuli (NMDA and sensory stimulation) that induce $\left[\mathrm{Ca}^{2+}\right]_{\mathrm{e}}$ decreases and neuronal bursting. We identified astrocytes by specific loading of sulforhodamine 101 (1 $\mu \mathrm{M}$ in the bath) and their lack of active membrane properties (Fig. 3a). Using simultaneous whole cell patch recordings and $\mathrm{Ca}^{2+}$ imaging, we observed that local NMDA (1mM) applications produced large increases of intracellular $\mathrm{Ca}^{2+}$ $(143.2 \pm 28.8 \% \Delta \mathrm{F} / \mathrm{F})$ accompanied by depolarizations (6.6 $\pm 1.2 \mathrm{mV} ; n=5$ astrocytes; Fig. 3b) under current clamp conditions. Consistently, NVsnpr astrocytes were also depolarized by repetitive stimulation $(40-60 \mathrm{~Hz} ; n=$ 5 ) of the glutamatergic ${ }^{21}$ sensory fibers (Fig. 3b). Addition of TTX to the perfusing medium had little effect on the amplitude of the NMDA-induced membrane depolarization in astrocytes ( $1 \mu \mathrm{M}$; Fig. 3c, e; $n=9 / 9$ ), while addition of a mix of drugs blocking AMPA receptors, sodium channels, calcium channels and glutamate uptake (CNQX $10 \mu \mathrm{M}$, TTX $1 \mu \mathrm{M}$, cadmium 100 $\mu \mathrm{M}$, and PDC $50 \mu \mathrm{M})$ reduced the NMDA induced response by $53 \%$ in average (Fig. 3d-e; $n=5$ ) and abolished $(n=2)$ or greatly reduced (by $93 \%, n=1$ ) synaptic responses to electrical stimulation of the sensory fibers (Fig. $\mathbf{3 d - e )}$. The remaining response to NMDA in this condition (with the mix of blockers) presumably resulted from isolated NMDA-evoked current.

To further test whether NVsnpr astrocytes express functional NMDA receptors, the NMDA receptor antagonist, MK-801 (2 mM) was added to the internal recording solution. In 11 astrocytes recorded in this condition, NMDA applied locally elicited much smaller depolarisations only in the first minutes after breaking into the cell in 3 of these cells. These responses disappeared after a few minutes of diffusion of MK-801 (Fig. 3f), while responses to local application of glutamate (1 $\mathrm{mM})$, used only as a control to test viability of the recorded cells, persisted in all 11 cells (Fig. 3f) ( $n=$ 11/11). These results clearly demonstrate that NMDAinduced activation of astrocytes did not depend on neuronal transmission and is at least partially mediated by direct activation of astrocytic NMDA receptors. 

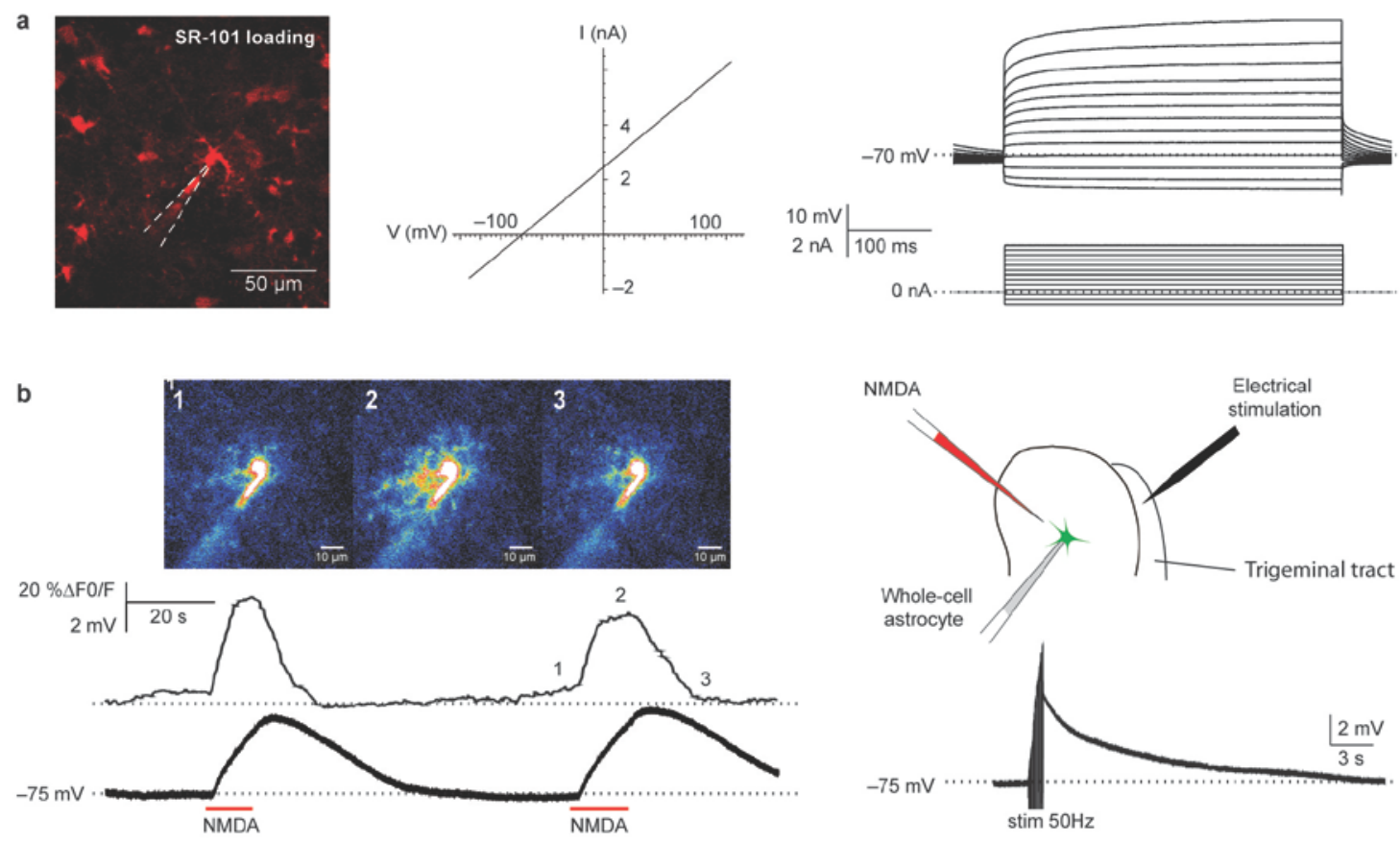

c

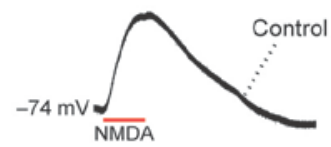

d
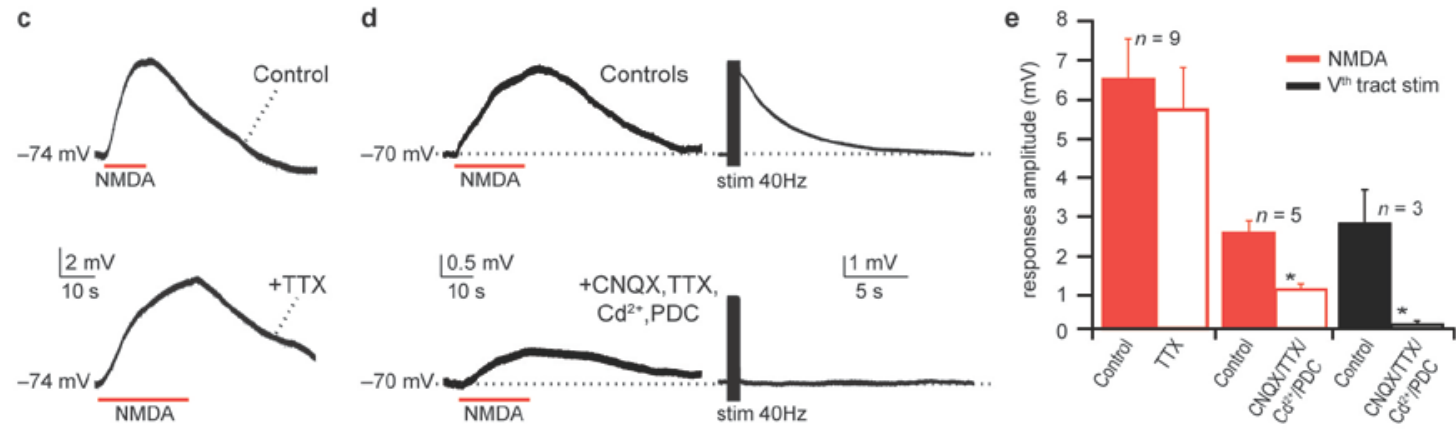
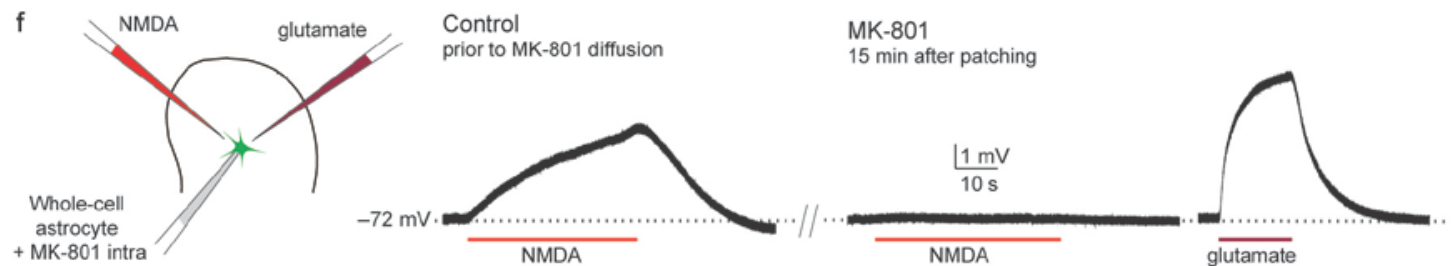

Figure 3: NVsnpr astrocytes have functional NMDA receptors and are activated by stimuli that cause $\left[\mathrm{Ca}^{2+}\right]_{\mathrm{e}}$ decreases and elicit neuronal rhythmic bursting. (a) Astrocytes were identified on the basis of their typical linear passive characteristics when imposing a depolarising ramp from $-130 \mathrm{mV}$ to $110 \mathrm{mV}$ in voltage clamp mode (middle) and the lack of action potentials in current clamp mode (right). In some experiments, the specific marker Sulforhodamine 101 (red cells in image, left), was also used. (b) Repeated local NMDA applications induced reproducible $\mathrm{Ca}^{2+}$ responses (left: top and middle, fluo-4; $100 \mu \mathrm{M}$ ) and concomitant membrane depolarisations (bottom left) ( $n=5$ astrocytes in 5 slices from 4 rats), while $50 \mathrm{~Hz}$ stimulation of the trigeminal tract induced membrane depolarisations of astrocytes (bottom right, $n=5$ cells in 5 slices from 5 rats). (c) Traces of depolarisations induced by local applications of NMDA under control conditions (top) and in presence of TTX $(1 \mu \mathrm{M}$; bottom $)(n=9$ of 9 cells in 9 slices from 6 rats). (d) Traces of depolarisations induced by local applications of NMDA (left, $n=5$ cells in 5 slices from 5 rats) and stimulation of sensory afferents at $40 \mathrm{~Hz}$ (right, $\mathrm{n}=3$ cells in 3 slices from 2 rats) under control conditions (top) and in presence of a mix of drugs (bottom) blocking AMPA receptors (CNQX, $10 \mu \mathrm{M})$, glutamate uptake (PDC, $50 \mu \mathrm{M}), \mathrm{Ca}^{2+} \mathrm{channels}\left(\mathrm{Cd}^{2+}, 100\right.$ $\mu \mathrm{M})$ and $\mathrm{Na}^{+}$channels $(\mathrm{TTX}, 1 \mu \mathrm{M})$. (e) Histograms show the effects of the different blockers on the amplitude of the depolarisations elicited by NMDA (paired t-test; $P=0.002$ ) ${ }^{\star} P<0.05$ or sensory fibers stimulation (paired t-test; $P=0.043 ;{ }^{*} P<0.05$ ). (f) Local applications of NMDA $(1 \mathrm{mM})$ caused membrane depolarisation in an astrocyte immediately after entering the cell with a pipette filled with the NMDA receptor antagonist MK-801 (left), but no longer after $15 \mathrm{~min}$ of diffusion of MK-801 (middle), while glutamate $(1 \mathrm{mM})$, which was used to ensure viability of the cell, still elicited a robust response after 15 min of diffusion (right) ( $n=11$ cells in 9 slices from 6 rats). 


\section{Inactivation of astrocytes prevents neuronal bursting} Astrocytes are coupled through gap junctions and form syncytia as shown by dye diffusion in Fig. 4a. Hence, a $\mathrm{Ca}^{2+}$-chelating agent introduced in one astrocyte by a patch pipette will diffuse to neighbouring astrocytes ${ }^{22}$ and prevent astrocytic activity resulting from changes in cytosolic $\mathrm{Ca}^{2+}$. Under control conditions, local application of NMDA induced widespread $\mathrm{Ca}^{2+}$ responses in cells loaded with a membrane permeant form of $\mathrm{Ca}^{2+}$ indicator, that were also positively labelled as astrocytes with SR101 (Fig. 4b). However, as shown in Fig. 4c, BAPTA introduced in a single astrocyte prevented $\mathrm{Ca}^{2+}$ dependent astrocytic activation of nearby astrocytes that were presumably coupled. Indeed, in 8 experiments, a total of 26 cells showed an intracellular $\mathrm{Ca}^{2+}$ increase in response to NMDA. Patching a single astrocyte in each experiment with a BAPTA-loaded electrode (20-35 mM) resulted in a loss of $>75 \%$ of the original response to NMDA in 23 of the 26 cells.

To test whether inactivation of the astrocytic syncytium interferes with neuronal bursting, we performed dual recordings of a neuron and an adjacent astrocyte and assessed the neuronal bursting ability when BAPTA was added in the electrode used to record from the astrocyte. In 19 such pairs, local application of NMDA in the first few minutes of recording depolarized both the astrocyte and the neuron and led to rhythmic bursting if the neuron had been hyperpolarized prior to the application (Fig. 5a-b). However, in 16 of the 19 pairs, NMDA still depolarized neurons and astrocytes after diffusion of BAPTA in the syncytium, but could no longer elicit rhythmic bursting (insets of Fig. 5a-5c) even when further hyperpolarization was imposed to the neuron. In the 3 remaining cases, NMDA applications still elicited bursting even after BAPTA diffusion in the syncytium. This apparent lack of effect may result from impaired network integrity in the slice preparation. It is noteworthy that repeated NMDA applications caused reproducible bursting in neurons and $\mathrm{Ca}^{2+}$ increases in astrocytes recorded under control conditions over extended periods of time (Fig. 5d). In 3 additional pairs in which either a second neuron, another type of glial cell or a distant astrocyte was inadvertently patched and dialysed with BAPTA, NMDA-induced neuronal bursting persisted even after up to 90 min of BAPTA diffusion. In 4 additional paired recordings, dialysis of the astrocytes with a much lower concentration of BAPTA $(0.1 \mathrm{mM})$ did not alter neuronal bursting for over $60 \mathrm{~min}$ (Supplementary Fig. 4a).

Knowing that astrocytes are important for bursting and that reduction of $\left[\mathrm{Ca}^{2+}\right]_{\mathrm{e}}$ facilitates $\mathrm{I}_{\mathrm{NaP}}{ }^{-}$ mediated bursting, we postulated that artificially reducing $\left[\mathrm{Ca}^{2+}\right]_{\mathrm{e}}$ should occlude the effect of BAPTA diffusion in the astrocytic syncytium. Indeed, in 3 pairs recorded in $\mathrm{Ca}^{2+}$-free aCSF, neuronal bursting persisted after letting BAPTA (20 mM) diffuse in the astrocytic syncytium for more than $1 \mathrm{hr}$ (Supplementary Fig. 4b). a

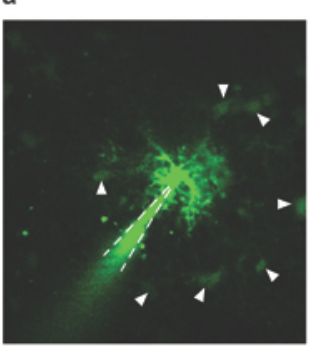

Intrapipette alexa-488

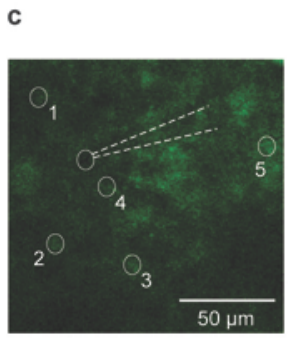

b
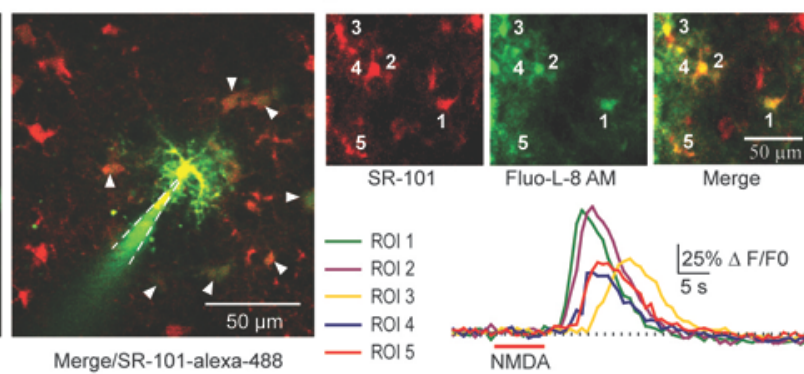

ROI 1
ROI 2
ROI 3
ROI 4
ROI 5

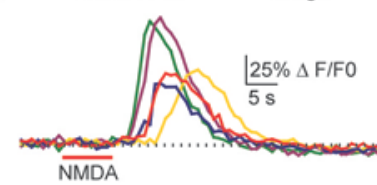

$\overline{\text { NMDA }}$

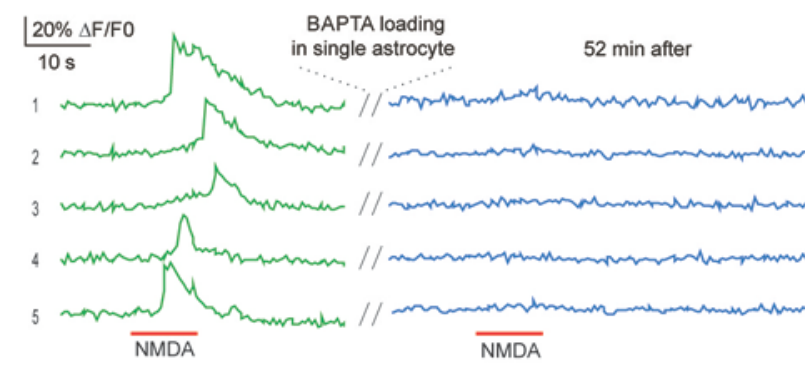

Figure 4: NVsnpr astrocytes are coupled and can be inactivated by introduction of BAPTA in the syncytium. (a) Coupling between astrocytes is revealed by diffusion of the tracer Alexa-488 (100 $\mu \mathrm{M}$; green cells, arrow heads) added to the internal solution of an electrode used to patch a single astrocyte and spreading to neighbouring astrocytes (arrowheads) preloaded with SR101 (red) (double-labeled cells, right). (b) Single local NMDA application elicited $\mathrm{Ca}^{2+}$ responses in several astrocytes as shown by the co-localisation (merge) of the membrane permeant indicator, fluo-L8 AM (green) with SR101 (red) in the top panel. Bottom: $\mathrm{Ca}^{2+}$ responses in different astrocytes defined in regions of interest (ROI). (c) After incubation with the membrane permeant $\mathrm{Ca}^{2+}$-indicator, fluo-L8 AM, several cells (defined by circles and numbers in the left image) responded to a single NMDA application (green traces). $\mathrm{Ca}^{2+}$-responses to NMDA application were blocked in all cells after patching a single astrocyte with a BAPTA-filled (20 mM) pipette (blue traces). Mean intracellular $\mathrm{Ca}^{2+}$ increase before BAPTA: $51.3 \pm 4$ vs after BAPTA: $14.2 \pm 3 \% \Delta F / F 0, n=26$ cells, paired t-test $P=$ 1.082E-07. 
a Before patching the astrocyte
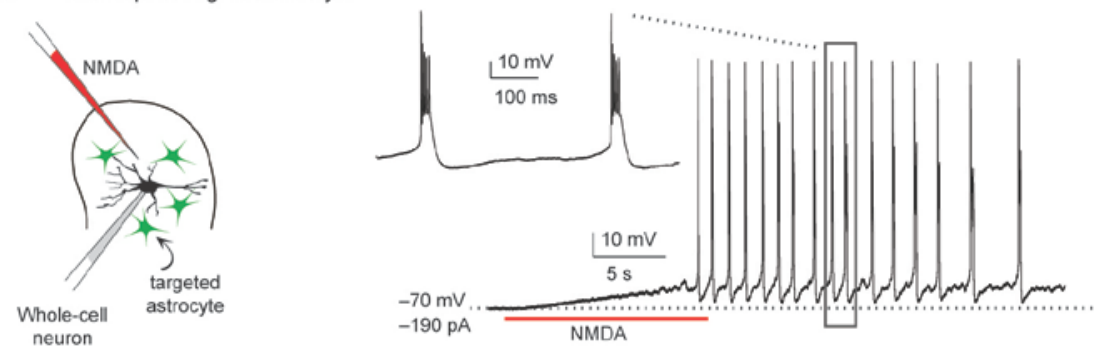

b Immediatly after patching the astrocyte

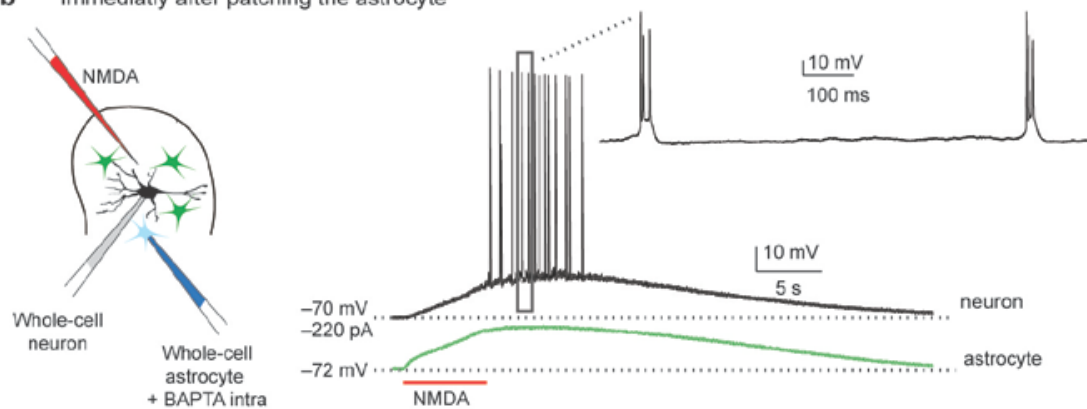

C After BAPTA diffusion within the astrocytic syncytium
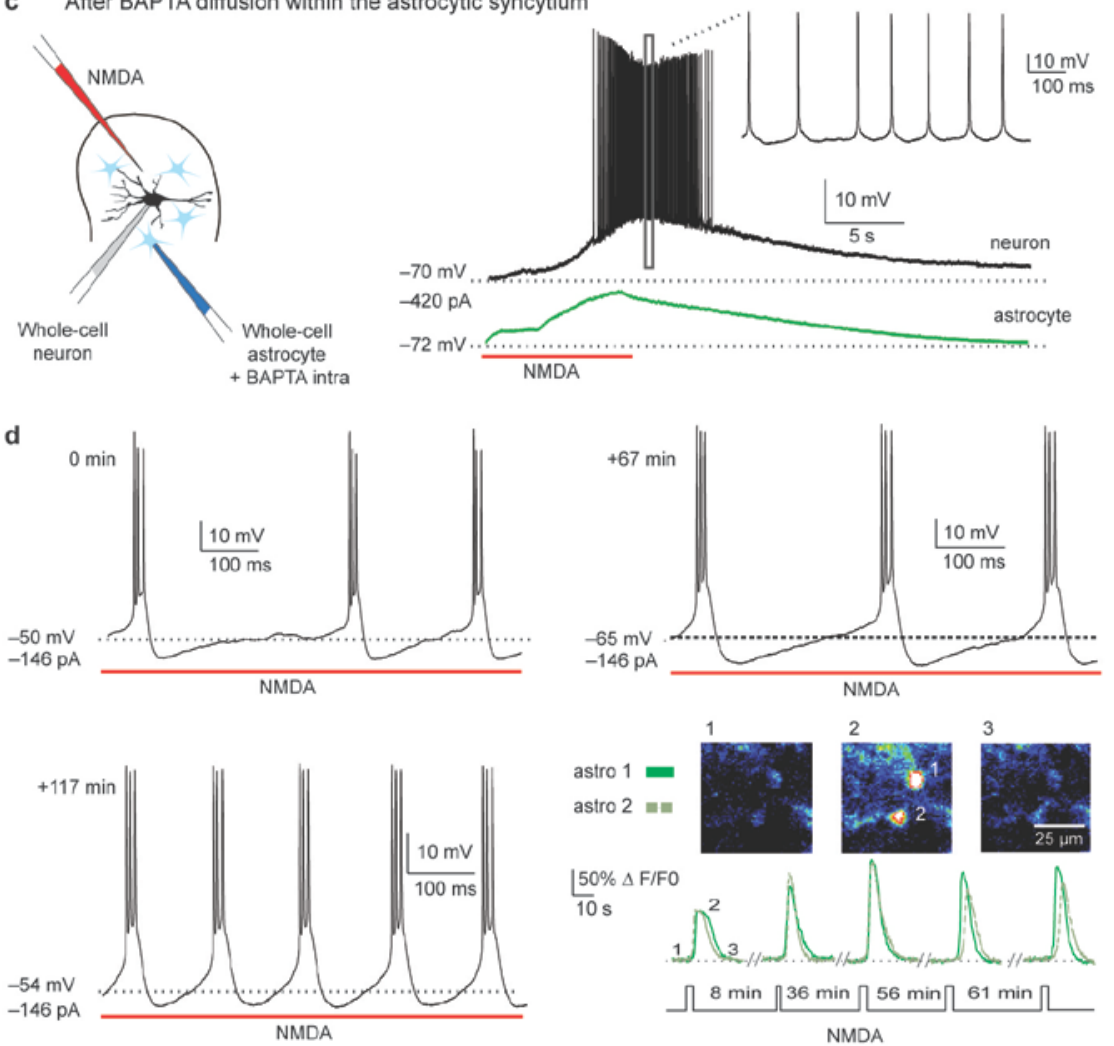

Figure 5 : Inactivation of the astrocytic syncytium by diffusion of BAPTA impedes neuronal bursting. (a) Local NMDA application induced burst firing in an NVsnpr neuron before recording of an adjacent astrocyte with a BAPTA-filled pipette (20 mM). (b) NMDA applied immediately (<3 min) after breaking into the astrocyte using the BAPTA filled electrode still elicited burst firing in the NVsnpr neuron (top), with a concomitant depolarization of the recorded astrocyte (green traces, bottom). (c) After diffusion of BAPTA in the astrocytic syncytium (> 30 $\mathrm{min}$ ), NMDA failed to elicit bursting, despite maintaining a depolarizing effect on the recorded neuron and astrocyte ( $\mathrm{n}=16$ of 19 pairs in 19 slices from 19 rats). (d) In control conditions, rhythmic bursting could be elicited repetitively by NMDA applications in NVsnpr neurons recorded over long periods of time; $117 \mathrm{~min}$ in this case. Similarly, calcium responses could be induced consistently in fluo-L-8 AM loaded astrocytes with repeated NMDA applications over long periods of time (Bottom right panel). Calcium responses are shown in pseudo-colors. 
S100 $\beta$ induces bursting, reduces $\left[\mathrm{Ca}^{2+}\right]_{\mathrm{e}}$ and enhances $\mathrm{I}_{\mathrm{NaP}}$

We next investigated the mechanisms by which astrocytes could alter $\left[\mathrm{Ca}^{2+}\right]_{\mathrm{e}}$. S100 $\beta$ is a prime candidate due to its glial specificity, its established $\mathrm{Ca}^{2+}$-binding properties and its secretion by astrocytes ${ }^{23,24}$. As could be expected, immunostaining with an antibody directed against $S 100 \beta$ revealed numerous immunoreactive astrocytes in dorsal NVsnpr (Supplementary Fig. 5; $n=2$ animals). To assess the effects of this protein, we first synthesized it using a recombination approach and tested its binding to $\mathrm{Ca}^{2+}$ with isothermal titration calorimetry (ITC). A clear endothermic binding of calcium to this $S 100 \beta$ was observed with an apparent dissociation constant $\left(K_{D}\right)$ of $25 \mu \mathrm{M}$ and a stoichiometry of 2 calcium molecules for each molecule of protein, indicating that the synthesized $S 100 \beta$ adopts its calcium bound form (Supplementary Fig. 6a).

To test the effects of $S 100 \beta$ on neuronal firing and on $\left[\mathrm{Ca}^{2+}\right]_{\mathrm{e}}$, we suspended the synthesized protein in a $20 \mathrm{mM}$ Hepes buffer containing $140 \mathrm{mM} \mathrm{NaCl}$ and applied it locally at the concentration of $129 \mu \mathrm{M}$ in submerged recording chamber and $50 \mu \mathrm{M}$ in the interface chamber. In this initial set of experiments, the buffer used to suspend $\mathrm{S} 100 \beta$ was devoid of $\mathrm{Ca}^{2+}$ to prevent saturation of the protein and preserve its $\mathrm{Ca}^{2+}$ binding ability. Consistent with this ability, we found that $\mathrm{S} 100 \beta$ applied locally in submerged preparations (bathed in aCSF containing $1.6 \mathrm{mM} \mathrm{Ca}{ }^{2+}$ ) caused large decreases in $\left[\mathrm{Ca}^{2+}\right]_{\mathrm{e}}$ as measured with ion-sensitive electrodes (reduction of $1.0 \pm 0.1 \mathrm{mM}, n=15$, Fig. 6a-b). As with BAPTA and NMDA, local extracellular applications of $S 100 \beta$ caused neurons recorded in both interface and submerged chambers, to change their firing pattern from tonic to rhythmic bursting ( $n=62 / 76$; Fig. 6a). Dual recordings of intracellular activity and $\left[\mathrm{Ca}^{2+}\right]_{\mathrm{e}}$ with ionsensitive electrodes revealed that the transition from tonic to bursting firing appeared gradually and paralleled the $\mathrm{Ca}^{2+}$ decrease ( Fig. 6a-b, $n=5$ ). Doublets firing (shown in Supplementary Fig. 1 and described in Material and Methods) appeared, intermingled with single spikes at $\left[\mathrm{Ca}^{2+}\right]_{e}$ of $0.9 \pm 0.27 \mathrm{mM}$. At higher concentrations, only tonic (single spikes) firing was observed, and at a $\left[\mathrm{Ca}^{2+}\right]_{\mathrm{e}}$ of $0.69 \pm 0.19 \mathrm{mM}$, only doublets were observed. Bursts (triplets) mingled with doublets appeared at $\left[\mathrm{Ca}^{2+}\right]_{e}$ of $0.54 \pm 0.16 \mathrm{mM}$ and only bursts were seen at $\left[\mathrm{Ca}^{2+}\right]_{\mathrm{e}}$ of $0.4 \pm 0.13 \mathrm{mM}$ and less. Interestingly, the frequency of the $\mathrm{S} 100 \beta$-induced bursting is similar to that of bursting obtained following sensory fibers stimulation when tested in the interface chamber, and to that of NMDA-induced bursting when tested in submerged preparations (Table 1). S100 $\beta$ can have multiple effects but the above-results suggest that it promotes neuronal bursting by lowering $\left[\mathrm{Ca}^{2+}\right]_{\mathrm{e}}$. A series of experiments was undertaken to verify this and to determine if the $\mathrm{Ca}^{2+}$-free solution in which it was suspended had some effects on its own. First, local applications of the $\mathrm{Ca}^{2+}$-free buffer alone caused a small decrease of $\left[\mathrm{Ca}^{2+}\right]_{\mathrm{e}}(0.55 \pm 0.09 \mathrm{mM} ; n=6$; Supplementary Fig 7a), but did not alter the neuronal firing pattern in extracellular recordings in the interface chamber $(n=11$; Supplementary Fig $7 b)$ and in intracellular recordings in the submerged configuration ( $n=3$; Supplementary Fig 7c). Second, saturating the $\mathrm{Ca}^{2+}$ binding activity of $\mathrm{S} 100 \beta$ by increasing to $2.6 \mathrm{mM}$ the $\left[\mathrm{Ca}^{2+}\right]$ in the circulating aCSF prevented induction of bursting by local applications of the protein suspended in $\mathrm{Ca}^{2+}$-free solution $(n=4$; Supplementary Fig 7d). Similarly, $\mathrm{S} 100 \beta$ suspended in a buffer containing $1.6 \mathrm{mM}$ $\mathrm{Ca}^{2+}$ had no effects on firing at the concentration used throughout the study ( $129 \mu \mathrm{M} ; n=5$; Supplementary Fig. 7e), and not surprisingly the buffer itself containing 1.6 $\mathrm{mM} \mathrm{Ca}^{2+}$ had no effect by itself on neuronal firing $(n=3$ in 2 slices from 2 rats) and on $\left[\mathrm{Ca}^{2+}\right]_{\mathrm{e}}(n=4$ in 2 slices from 2 rats; data not shown). However, raising the concentration of the protein to $1 \mathrm{mM}$ to overcome its saturation in the $\mathrm{Ca}^{2+}$-containing buffer, restored its effects on neuronal firing and on $\left[\mathrm{Ca}^{2+}\right]_{\mathrm{e}}$. Local applications of this solution containing $1 \mathrm{mM}$ of $\mathrm{S} 100 \beta$ suspended in a buffer containing $1.6 \mathrm{mM}\left[\mathrm{Ca}^{2+}\right]$ induced bursting in all 10 cells (Supplementary Fig. 7e) tested in the submerged configuration and caused large decreases in $\left[\mathrm{Ca}^{2+}\right]_{\mathrm{e}}$ (reduction of $1.27 \pm 0.05 \mathrm{mM}, n=8$ applications; Fig. 6c). Finally and most importantly, to insure that these effects of $S 100 \beta$ can be attributed to its $\mathrm{Ca}^{2+}$-binding ability, we tested the effects of an $\mathrm{S} 100 \beta$ protein with two mutated residues obliterating its $\mathrm{Ca}^{2+}$ binding ${ }^{25}$. Local applications of a solution containing $1 \mathrm{mM}$ of this mutated protein suspended in a $20 \mathrm{mM}$ Hepes buffer containing $140 \mathrm{mM} \mathrm{NaCl}$ and $1.6 \mathrm{mM} \mathrm{CaCl}_{2}$, had no effect on neuronal firing pattern of 7 cells recorded in the submerged configuration and caused only a marginal decrease of $\left[\mathrm{Ca}^{2+}\right]_{\mathrm{e}}(0.15 \pm 0.02 \mathrm{mM} ; n=$ 7; Fig. 6d). These are very strong evidence that $S 100 \beta$ effects on neuronal firing pattern result from its ability to bind $\mathrm{Ca}^{2+}$ and to decrease its extracellular concentration which in turn enhances $I_{\mathrm{NaP}}$ and favors bursting. In all following experiments, $S 100 \beta$ was used at the lower concentration in the submerged chamber $(129 \mu \mathrm{M})$ and was suspended in the $\mathrm{Ca}^{2+}$-free buffer. We use riluzole to ascertain that the $S 100 \beta$-induced bursting involved $I_{\mathrm{NaP}}$. Blockade of $I_{\mathrm{NaP}}$ channels with riluzole indeed prevented bursting induced by local application of $\mathrm{S} 100 \beta$ (Fig. 6e; $n$ $=7 / 10$ and $4 / 4$ in interface and submerged preparations, respectively). In 3 cases, riluzole did not block the $S 100 \beta$ induced bursting, probably because of an ineffective drug 
perfusion in the brain tissue since these instances occured only in the interface recording conditions. To further assess whether the burst-inducing action of $S 100 \beta$ could result from a modulation of $I_{\mathrm{NaP}}$, we examined its effects on the pharmacologically-isolated $I_{\mathrm{NaP}}$ current in voltage clamp experiments. As was the case for extracellular BAPTA, locally applied S100 $\beta$ significantly increased the peak amplitude of the isolated $\mathrm{I}_{\mathrm{NaP}}$ by $55 \pm 11 \%$ ( $n=7$; Fig. 6e and Supplementary Fig. 2b) and shifted the potential at which it occurred by $4 \%$ or $2 \mathrm{mV}(-44.7 \pm 1.3 \mathrm{mV}$ for controls vs $-46.6 \pm 1.9 \mathrm{mV}$ for $S 100 \beta)$. Again, the inward current induced under $\mathrm{S} 100 \beta$ was blocked with bath application of riluzole $(20$ $\mu \mathrm{M} ; n=3)$ or TTX (1-2 $\mu \mathrm{M} ; n=2$ cells in 2 slices from 2 rats). The characteristics of this current assessed by fitting a Boltzmann function gave values between those obtained in controls and those obtained under BAPTA (Supplementary Fig. 2d).
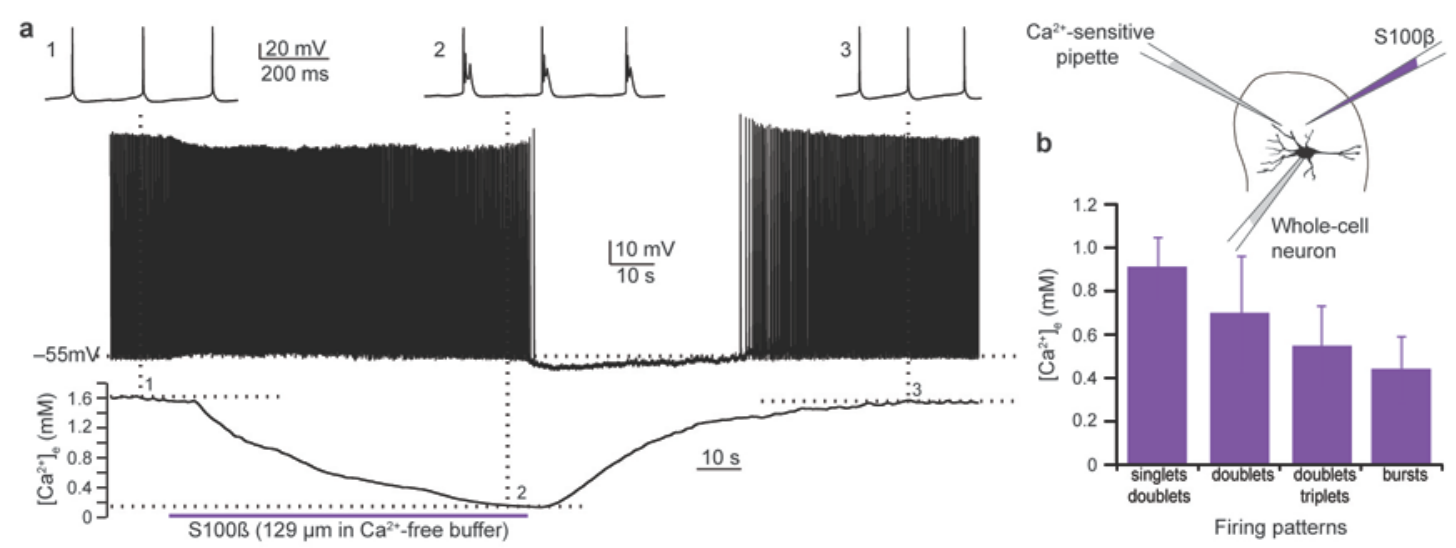

C

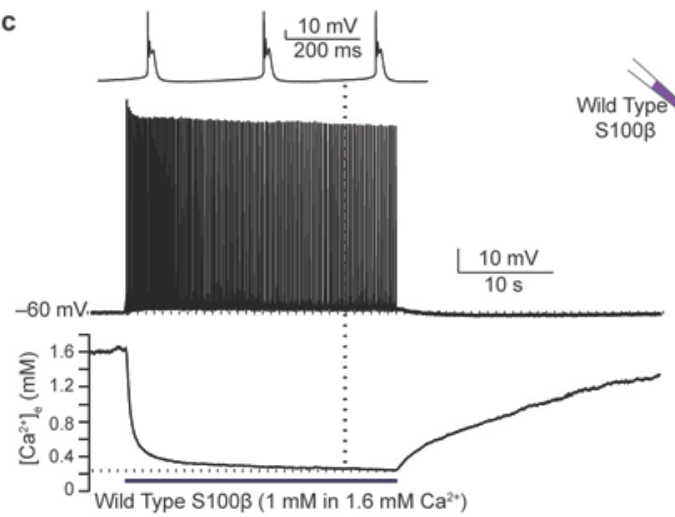

d

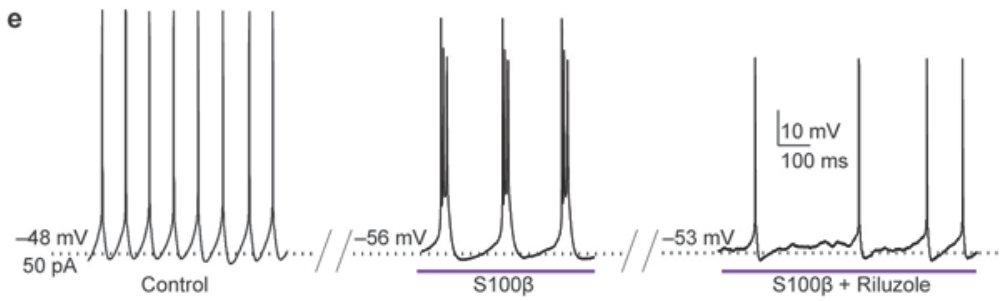

Mutated $\mathrm{S} 100 \beta\left(1 \mathrm{mM}\right.$ in $\left.1.6 \mathrm{mM} \mathrm{Ca}^{2 *}\right)$

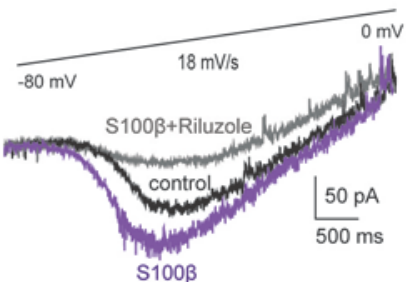

Figure 6: The astrocytic $\mathrm{Ca}^{2+}$ binding protein $\mathrm{S} 100 \beta$, causes $\left[\mathrm{Ca}^{2+}\right]_{\mathrm{e}}$ decreases, and induces $\mathrm{I}_{\mathrm{Nap}}$ dependent bursting. (a) Local application of $\mathrm{S} 100 \beta$ near an NVsnpr neuron (left; $129 \mu \mathrm{M}$ in $\mathrm{Ca}^{2+}$-free buffer) in a submerged preparation causes a transient decreases of $\left[\mathrm{Ca}^{2+}\right]_{e}\left(\mathrm{n}=15\left[\mathrm{Ca}^{2+}\right]_{e}\right.$ recording locations in 8 slices from 8 rats) and rhythmic bursting in an adjacent neuron ( $n=62$ of 76 cells in 66 slices from 57 rats). Insets $\left(1,2 \text {, and } 3 \text { ) show the firing pattern of the neuron on a larger time scale at the } 3 \text { corresponding times on the [Ca }{ }^{2+}\right]_{e}$ trace. (b) The histograms show changes in firing patterns with $\left[\mathrm{Ca}^{2+}\right]_{e} \quad(n=5$ cells in 5 slices from 5 animals). (c) Similar effects on firing ( $n=10$ of 10 cells) and $\left[\mathrm{Ca}^{2+}\right]_{e}(n=8$ recording locations) could be elicited by local application of a wild type $\mathrm{S} 100 \beta$ suspended in a solution containing $1.6 \mathrm{mM} \mathrm{Ca}^{2+}$, but only if the concentration of the protein was raised to $1 \mathrm{mM}$ to avoid its saturation (in 4 slices from 4 rats). (d) Local application of a recombinant $\mathrm{S} 100 \beta\left(1 \mathrm{mM}\right.$, in a buffer containing $\left.1.6 \mathrm{mM} \mathrm{Ca}^{2+}\right)$ with 2 mutated residues to prevent $\mathrm{Ca}^{2+}$-binding had no effect on firing and caused only marginal changes in $\left[\mathrm{Ca}^{2+}\right]_{e}\left(n=7\right.$ cells and 7 adjacent $\left[\mathrm{Ca}^{2+}\right]_{e}$ recording locations in 2 slices from 2 rats). (e) The $S 100 \beta$-induced bursting (middle) is abolished in presence of $\mathrm{I}_{\mathrm{Nap}}$ blocker, riluzole ( $20 \mu \mathrm{M}$, right, $\mathrm{n}=11 / 14$ cells in 14 slices from 11 rats). Left: Voltage clamp recordings of a pharmacologically isolated inward current induced by a voltage ramp from -80 to $0 \mathrm{mV}$ (top trace). The inward current elicited under control conditions (black) is increased by local application of $S 100 \beta$ (purple; $n=7$ cells in 7 slices from 5 rats; control: $88 \pm 26$ vs $S 100 \beta$ : $135 \pm 41 \mathrm{pA}$; paired t-test; $P=0.021)$ and blocked by riluzole $(20 \mu \mathrm{M} ;$ grey, $n=3$ cells in 3 slices from 2 rats $)$. 
If changes in neuronal firing and $\left[\mathrm{Ca}^{2+}\right]_{\mathrm{e}}$ induced by NMDA and sensory fibers stimulation depended on $S 100 \beta$ and if $S 100 \beta$ release is downstream of NMDA and/or other glutamatergic receptors activation, then blocking astrocytes with BAPTA should prevent NMDAinduced but not S100ß-induced bursting. Indeed, in paired recordings of neurons and adjacent astrocytes with BAPTA in the electrode used for the astrocyte, local applications of NMDA and of S100 $\beta$ separately both induced rhythmic bursting in the first few minutes (Fig. 7a). NMDA-induced bursting was gradually blocked by diffusion of BAPTA in the astrocytic syncytium, while S100 $\beta$-induced bursting persisted unaltered for as long as the cell was held (20-80 min after blockade of NMDAinduced bursting, $n=5 / 5$; Fig. 7b).

\section{Blockade of $S 100 \beta$ prevents bursting induced by sensory fiber stimulation or NMDA}

The above data suggest that $S 100 \beta$ can still elicit bursting after inactivation of the astrocytic syncytium but do not prove that $S 100 \beta$ is required for bursting. So we tested whether blocking extracellular $S 100 \beta$ activity with a local application of an S100ß-subunit monoclonal antibody $(40-80 \mu \mathrm{g} / \mathrm{ml})^{24}$ prevented bursting induced by NMDA applications or sensory fibers stimulation. To insure that the antibody interferes with the $\mathrm{Ca}^{2+}$ binding ability of
S100 $\beta$, we used ITC. Indeed, no difference in the generated heat was observed when $\mathrm{Ca}^{2+}$ was added to $S 100 \beta$ in the presence of the anti-S100 $\beta$ monoclonal antibody, indicating that the antibody binding to $S 100 \beta$ inhibited calcium binding (Supplementary Fig. 6b). In 4/4 slices examined in the interface chamber, pre-treatment with this antibody prior to stimulation of the sensory fibers prevented neuronal bursting and $\left[\mathrm{Ca}^{2+}\right]_{\mathrm{e}}$ decreases measured with ion-sensitive electrodes ( Fig. 8a). In 2 additional cases, similar pre-treatment with a nonspecific antibody (donkey anti-sheep IgG) did not prevent the $\mathrm{Ca}^{2+}$ decrease, nor the accompanying neuronal bursting ( Fig. 8b) induced by sensory fibers stimulation. More importantly, in 11 cells recorded in submerged slices, rhythmic bursting induced by NMDA was totally ( $n$ = 7; Fig. 8c) or partially $(n=2)$ blocked by treatment with the anti-S100 $\beta$ antibody, except in 2 cases. In the 2 cases considered as partially blocked, NMDA applications elicited a few irregular bursts with a much shorter duration when compared to those elicited prior to application of the antibody. Use of the non-specific antibody did not prevent bursting induced by NMDA in $5 / 5$ cases (Fig. 8d). These data strongly suggest that sensory fibers stimulation and NMDA-induced neuronal bursting depend on the presence of $S 100 \beta$ in the extracellular space and its capacity to bind $\mathrm{Ca}^{2+}$.
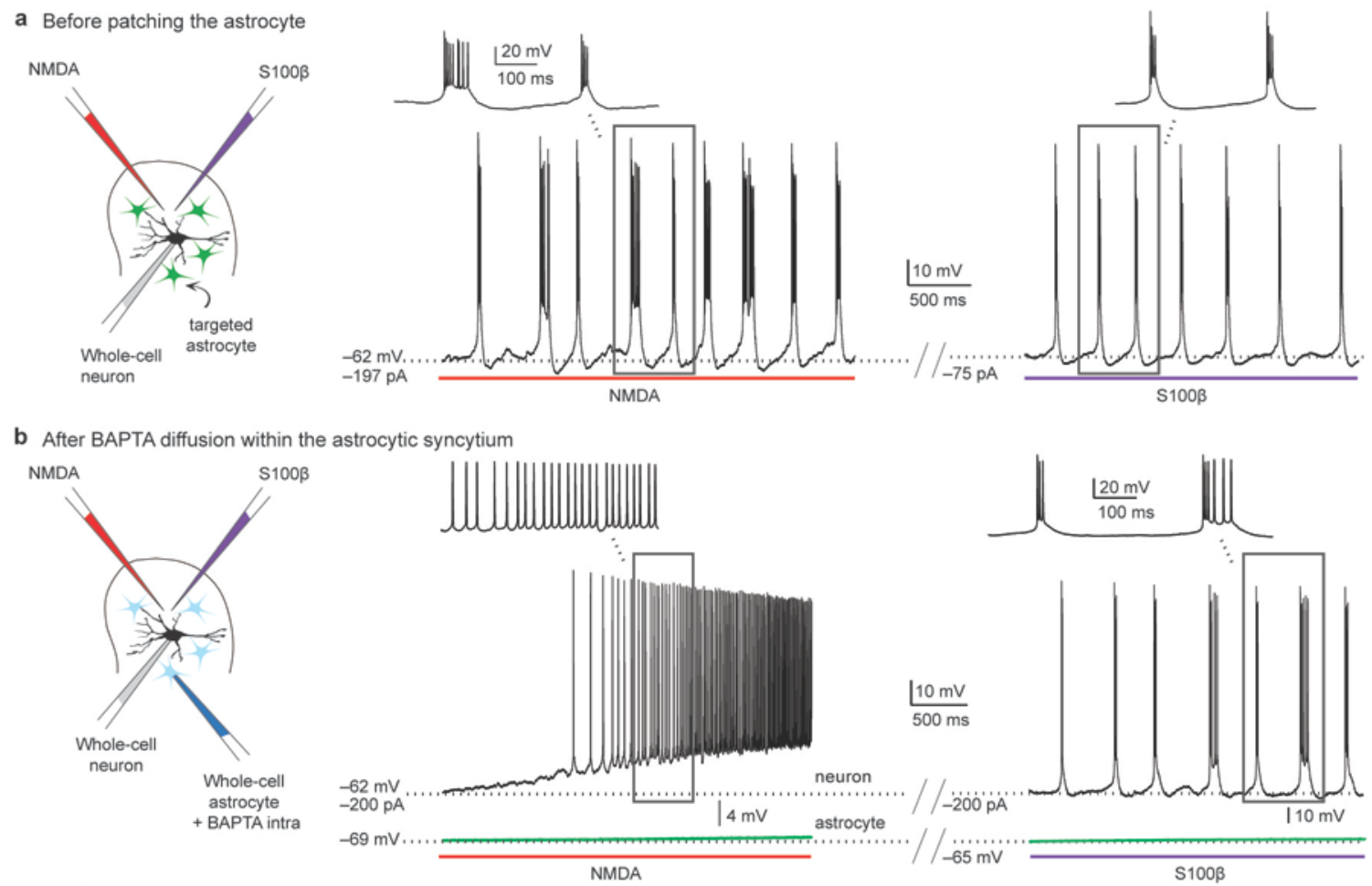

Figure 7: S100ß-induced bursting persists after inactivation of the astrocytic syncytium with BAPTA. (a) Exogenously-applied NMDA and $\mathrm{S} 100 \beta$ both induced burst firing in an NVsnpr neuron prior to dialysis of an adjacent astrocyte with BAPTA. (b) After BAPTA diffusion in the astrocytic syncytium, NMDA applied to the same neuron had a clear excitatory effect but no longer elicited rhythmic bursting (left), while $S 100 \beta$ could still induce bursting (right) ( $n=5$ of 5 pairs in 5 slices from 5 rats). 

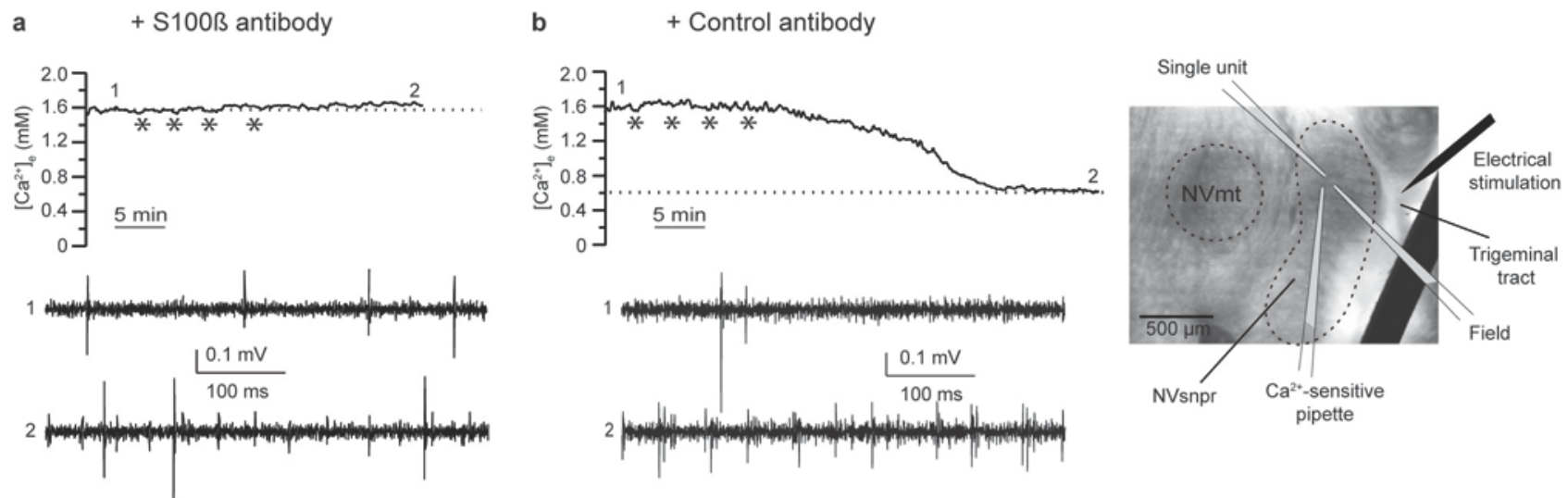

C

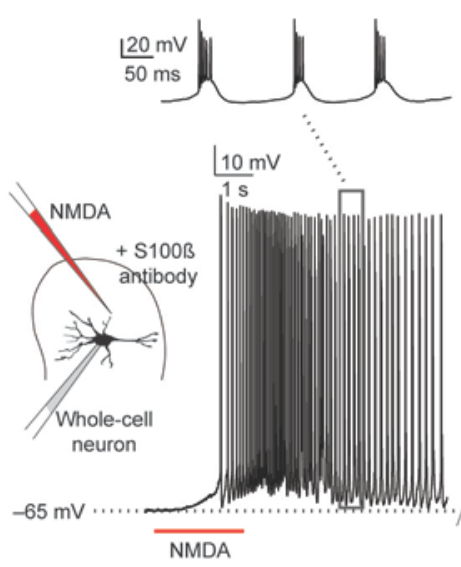

$+\mathrm{S} 100 ß$ antibody
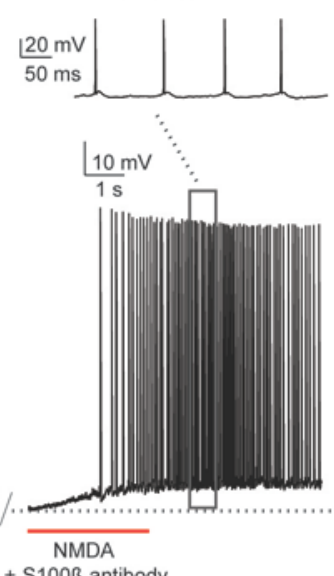

d
+ Control antibody

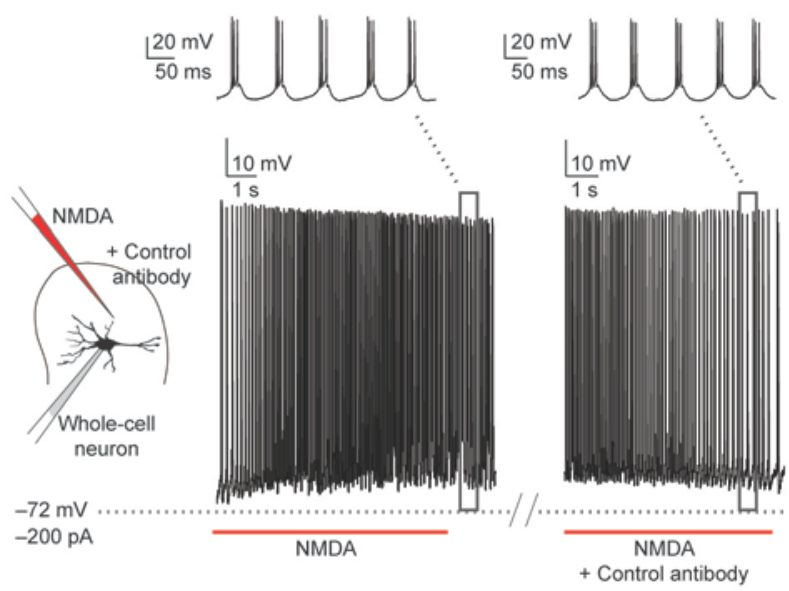

Figure 8 : The presence of $S 100 \beta$ in the extracellular space is required for bursting to occur in NVsnpr. (a) Inhibiting extracellular endogenous $\mathrm{S} 100 \beta$ activity with $\mathrm{S} 100 \beta$ antibody prevented the $[\mathrm{Ca} 2+]$ e decrease (top) following repetitive electrical stimulation (4 trains $\left({ }^{*}\right) ; 40 \mathrm{~Hz}$, $1 \mathrm{~s}$ ) of the trigeminal tract ( $\mathrm{n}=4$ cells and 4 adjacent [Ca2+]e recording locations in 4 slices from 3 rats). Bottom: In the same preparation, the tonic firing pattern of a spontaneously active neuron (1), recorded near the Ca2+-sensitive electrode, was unaltered by the stimulation in presence of the antibody (2). 1 and 2 are recordings of the neuronal activity at times corresponding to parts 1 and 2 on the [Ca2+] record above. (b) Local application of an unrelated antibody (directed against sheep lgG) did not prevent the [Ca2+]e decrease (top) and switch to burst firing (bottom) induced by repetitive stimulation of the trigeminal tract ( ${ }^{*} 1 \mathrm{~s}$ trains at $\left.40 \mathrm{~Hz}\right)(\mathrm{n}=2$ cells and 2 adjacent [Ca2+]e recording locations in 2 slices from 2 rats). (c) Similarly, in an NVsnpr neuron, NMDA induced burst firing (left) was blocked by local application of the anti-S100 $\beta$ antibody [40 $\mu \mathrm{g} / \mathrm{ml}$ ], resulting in tonic increase of firing without bursting (right) ( $\mathrm{n}=11$ cells in 11 slices from 10 rats). (d) NMDA-induced rhythmic bursting (left) was unaltered by local application of the $S 100 \beta$ unrelated antibody (directed against sheep lgG) ( $n=5 / 5$ cells in 5 slices from 4 rats).

\section{DISCUSSION}

The results presented here uncover a novel mechanism for rhythmogenesis that depends on proper functioning of the astrocytes. The key element of this mechanism is regulation of $I_{\mathrm{Nap}}$, the ionic conductance driving neuronal rhythmic burst firing by decreases of $\left[\mathrm{Ca}^{2+}\right]_{\mathrm{e}}$. Changes in $\left[\mathrm{Ca}^{2+}\right]_{\mathrm{e}}$ follow stimulation of afferent inputs to NVsnpr neurons and result from activation of astrocytes and presumed subsequent release of the Ca2+-binding protein $\mathrm{S} 100 \beta$ which is required for bursting and $\left[\mathrm{Ca}^{2+}\right]_{\mathrm{e}}$ decreases to occur.

\section{Physiological induction of $\left[\mathrm{Ca}^{2+}\right]_{e}$ decreases and their implications on $I_{N a P}$-mediated bursting}

Given the widespread importance of calcium signalling in numerous intracellular processes, studies have focussed mainly on its regulation in the intracellular compartment. However, imposed artificial fluctuations of the extracellular $\mathrm{Ca}^{2+}$ in a variety of preparations have revealed spectacular effects of this ion on neurons excitability. In an attempt to determine whether large changes in extracellular $\mathrm{Ca}^{2+}$ can be expected to occur in the brain, Egelman and Montague $(1999)^{26}$, using a computational approach came to the conclusion that large external $\mathrm{Ca}^{2+}$ fluctuations, leading to up to $100 \%$ depletion in many cases, must occur. Indeed, reduction of $\left[\mathrm{Ca}^{2+}\right]_{\mathrm{e}}$ have been reported to occur in parallel to $\left[\mathrm{K}^{+}\right]_{\mathrm{e}}$ increases during intense neuronal activity associated to 
seizures $^{10}$ or spreading depression ${ }^{27}$, or induced by massive electrical or pharmacological activation of the locomotor CPG and cerebellar cortex respectively ${ }^{11,28}$. The $\mathrm{Ca}^{2+}$ decreases reported in the above studies range between $0.1 \mathrm{mM}$ and $0.7 \mathrm{mM}$ and are of smaller magnitude than those reported here following stimulation of the trigeminal tract at a frequency close to the natural firing frequency of intra-oral afferents during mastication ${ }^{12}$. The difference in the measured $\left[\mathrm{Ca}^{2+}\right]_{\mathrm{e}}$ drops may result from different factors including the age of the animal, the baseline $\left[\mathrm{Ca}^{2+}\right]_{\mathrm{e}}$ used and the positioning of the ion-sensitive electrode in relation to the location where the $\left[\mathrm{Ca}^{2+}\right]_{\mathrm{e}}$ drops occur.

How $\left[\mathrm{Ca}^{2+}\right]_{\mathrm{e}}$ drops affect bursting is not exactly known. $\mathrm{Ca}^{2+}$-free perfusate has often been used to assess the role of synaptic transmission in various functions and, in many preparations, this procedure led to appearance of spontaneous burst discharges ${ }^{29,30}$. Although a link between this bursting and $I_{\mathrm{NaP}}$ had been described in supraoptic neurons ${ }^{17}$ and in hippocampus ${ }^{18}$, it was established in CPGs only recently by us in the masticatory system ${ }^{9}$, and later by others in the locomotor $\mathrm{CPG}^{8,11}$. This link is also likely to exist in at least part of the respiratory $\mathrm{CPG}$, since low $\mathrm{Ca}^{2+}$ perfusate is routinely used to obtain spontaneous bursting in in vitro preparations including the pre-Bötzinger complex where $I_{\mathrm{Nap}}$ is responsible for intrinsic bursting ${ }^{30}$. However, the fact that $I_{\mathrm{NaP}}$ mediated bursting is facilitated under low- $\mathrm{Ca}^{2+}$ conditions does not preclude that it may occur under physiological $\mathrm{Ca}^{2+}$ conditions as well. Indeed, our data with the sensory fibers stimulation suggest that neuronal activity can also produce $\mathrm{Ca}^{2+}$ decreases and $\mathrm{I}_{\mathrm{NaP}}$ dependent bursting.

The interaction between $\mathrm{Ca}^{2+}$ and $\mathrm{I}_{\mathrm{NaP}}$ is not fully understood, but work in the squid giant axon suggests that $\mathrm{Ca}^{2+}$ can occupy the pore of the sodium channel to favour its closing. In absence of $\mathrm{Ca}^{2+}$, closing slowed or did not occur. The voltage sensitivity of closing kinetics also changed with $\mathrm{Ca}^{2+}$ concentration, and seemed to depend in part on the ability of $\mathrm{Ca}^{2+}$ to enter and block the channels as voltage is driven negative ${ }^{31}$. This may partly explain why hyperpolarization was required to induce bursting when using NMDA. On one hand, hyperpolarization was required to keep the cells membrane potential within $I_{\mathrm{NaP}}$ activation range by counteracting the depolarization induced by NMDA. On the other, it may have helped relief the $\mathrm{Ca}^{2+}$ block of the $\mathrm{Na}^{+}$channel. In neurons of the supraoptic nucleus, removal of external $\mathrm{Ca}^{2+}$ shifted $\mathrm{I}_{\mathrm{NaP}}$ activation threshold by $\sim 13 \mathrm{mV}$ in a negative direction ${ }^{17}$, while in $\mathrm{Hb}$ geurons of the locomotor CPG, every $0.1 \mathrm{mM}$ decrease of $\mathrm{Ca}^{2+}$ shifted $I_{\mathrm{NaP}}$ activation threshold and half-activation voltage by $\sim 1 \mathrm{mV}$ towards more hyperpolarized potentials and, in both cases, $I_{\mathrm{NaP}}$ amplitude increased substantially ${ }^{11}$. This is in line with our data where local applications of BAPTA and S100 $\beta$, which both decrease $\left[\mathrm{Ca}^{2+}\right]_{\mathrm{e}}$, shift the activation and half-activation voltage of $\mathrm{I}_{\mathrm{NaP}}$ to the left. According to predictions based on a computational model of $\mathrm{Hb}$ cells, a slight shift of $\mathrm{I}_{\mathrm{NaP}}$ activation would suffice to cause tonically firing neurons to burst rhythmically ${ }^{11}$. Here, we found that bursting did not occur as long as $\left[\mathrm{Ca}^{2+}\right]_{\mathrm{e}}$ did not drop beneath $0.4 \mathrm{mM}$. Brocard et al. (2013) ${ }^{11}$ were able to induce bursting in the locomotor CPG at a $\left[\mathrm{Ca}^{2+}\right]_{\mathrm{e}}$ of $0.9 \mathrm{mM}$, but only if $\left[\mathrm{K}^{+}\right]$ was artificially raised to $6 \mathrm{mM}$. However, $I_{\mathrm{NaP}}$ currents were not upregulated by the increase of $\left[\mathrm{K}^{+}\right]_{\mathrm{e}}$. As suggested by Brocard et al. and previous work from Rybak et al. $(2003)^{32}$, the facilitation seen with increased $\left[\mathrm{K}^{+}\right]_{\mathrm{e}}$ probably results from a change in the potassium equilibrium potential $\left(E_{k}\right)$ that diminishes or supresses a delayed-rectifier potassium current. Also, we cannot discard regional or age related differences in $I_{\mathrm{NaP}}$ characteristics. Indeed, the mean peak amplitude that we observe was larger and occurred at more hyperpolarized potentials than those previously reported in NVsnpr neurons of younger animals (postnatal days 8$12)^{33}$.

\section{Function of astrocytes in regulating $\left[\mathrm{Ca}^{2+}\right]_{\mathrm{e}}$}

Our data suggest that in addition to NVsnpr neurons, sensory afferents stimulation at a frequency close to their natural firing frequency ${ }^{12}$ also activates astrocytes. Astrocytes have been shown to detect neurotransmitters release induced by basal ${ }^{34}$ as well as intense neuronal activity $^{35}$ and to respond by releasing gliotransmitters, modulating neuronal activity in return. Here we show that NVsnpr astrocytes have functional NMDA receptors that enable them to respond to the glutamate released by afferent fibers. Astrocytes in other brain regions have also been reported to have functional NMDA receptors ${ }^{36}$. Locally applied NMDA may act on neuronal NMDA receptors and/or on these astrocytic NMDA receptors causing release of other factors that may play a role in burst induction. Rhythmic bursting induced by NMDA has traditionally been ascribed to the biphasic I-V relationship of the current mediated by neuronal NMDA receptors $^{37,38}$. However, although we cannot rule out involvement of all neuronal NMDA receptors, our observations suggest that NMDA receptors of the recorded neuron itself are unlikely to play a significant role since neuronal NMDA receptors are normally blocked in hyperpolarized states and are mostly permeable to $\mathrm{Ca}^{2+}$. The fact that hyperpolarization was required for burst induction, and that the NMDA-induced bursting was insensitive to intraneuronal diffusion of BAPTA, suggest that NMDA receptors located elsewhere 
than on the recorded neuron are likely to be involved in the observed bursting.

We postulate that activation of astrocytes through their NMDA receptors and/or other glutamatergic receptors leads to $\left[\mathrm{Ca}^{2+}\right]_{\mathrm{e}}$ decreases since; i) the astrocytic syncytium must be functional and ii) $\left[\mathrm{Ca}^{2+}\right]_{\mathrm{e}}$ must decrease for bursting to occur. Modulation of $\left[\mathrm{Ca}^{2+}\right]_{\mathrm{e}}$ by astrocytes has often been postulated, but was never demonstrated. The fact that exogenous applications of a $\mathrm{Ca}^{2+}$-binding protein released by astrocytes, $\mathrm{S} 100 \mathrm{\beta}^{23,24}$, decrease $\mathrm{Ca}^{2+}$ and induce bursting even after inactivation of the astrocytic syncytium with BAPTA, is a clear indication, but not proof, that astrocytes act by releasing $S 100 \beta$. However, the fact that blockade of this protein with a specific antibody prevents $\left[\mathrm{Ca}^{2+}\right]_{\mathrm{e}}$ decreases and bursting induced with sensory fibers stimulation and NMDA applications is strong evidence that $S 100 \beta$ is required for bursting to occur. Furthermore, the secretion of $S 100 \beta$ from astrocytes has been reported to be stimulated by glutamate receptors activation as well as by intracellular calcium increase ${ }^{39}$, two conditions that are met in our experiments.

Surprisingly, despite its well-established $\mathrm{Ca}^{2+}$ binding property, previous studies that have focussed on $S 100 \beta$ extracellular actions have not addressed a possible regulatory role of local extracellular $\mathrm{Ca}^{2+}$ concentration. Intracellularly, $\mathrm{S} 100 \beta$ exerts many regulatory activities through $\mathrm{Ca}^{2+}$-dependent interactions with the cytoskeleton and with several cytoplasmic proteins involved in cell differentiation, proliferation and survival (for review ${ }^{39}$ ). Once released in the extracellular compartment, $\mathrm{S} 100 \beta$ exerts numerous actions via activation of RAGE (receptor for advanced glycation end products) ${ }^{39}$. We cannot rule out that these other effects of $S 100 \beta$ are important, but we can affirm that its effects on extracellular $\mathrm{Ca}^{2+}$ are required for bursting. Indeed, S100 $\beta$ loses its ability to alter neuronal firing once mutated at its $\mathrm{Ca}^{2+}$ binding sites and because inactivation of astrocytes with BAPTA in the $\mathrm{Ca}^{2+}$-free condition did not alter bursting. This latter finding also suggests that no other gliotransmitters that may be released from astrocytes in a $\mathrm{Ca}^{2+}$-dependent manner are required for bursting. In particular, our data argue strongly that a well-known gliotransmitter, ATP, is not likely involved owing to the lack of effect of Suramine, a broad antagonist of purinergic receptors on neuronal bursting.

\section{Functional significance: switch of neuronal function in territories defined by glial syncytia}

On the basis of these results, we propose a model where sustained synaptic inputs to NVsnpr arriving at a physiologically relevant frequency $(40-60 \mathrm{~Hz})$ initiate rhythmogenesis by activating both neurons and astrocytes (Supplementary Fig. 8). Sporadic or low frequency firing of the inputs is insufficient to activate the astrocytes. Under this condition, the circuit operates in a conventional sensory relay mode where the output is linearly related to the input (Supplementary Fig. 8). With more sustained activity at higher frequency, astrocytes get activated, couple to form a syncytium and release S100 $\beta$. The extent of the syncytium would define a territory (Blue circle in Supplementary Fig. 8) within which the confined neurons will be exposed to the same decrease in $\left[\mathrm{Ca}^{2+}\right]_{e}$, and, therefore have the same conditions of activation or inactivation of $I_{\mathrm{NaP}}$ channels. The terminals of inputs to NVsnpr are highly organized ${ }^{40}$ and are likely to activate adjacent neurons and astrocytes. Firing of these inputs could therefore act as a common trigger to initiate rhythmic activity in a given population of neurons which will be synchronized by the fact that they will be surrounded by the same astrocytic syncytium. The population of rhythmogenic neurons could vary constantly and in an adapted manner according to the pattern of incoming inputs. Interestingly, NVsnpr neurons also receive glutamatergic projections from the cortical masticatory area, known to be important for initiation of the movements and the first few cycles of a masticatory sequence ${ }^{41}$. Stimulation of this area elicits mastication in vivo but only when trains of stimuli are delivered at frequencies ranging between 20 and $100 \mathrm{~Hz}$ and optimally around 40-50 $\mathrm{Hz}^{42}$. Thus, NVsnpr neurons could be considered as an interface converting sensory and/or cortical inputs into rhythmic motor commands when astrocytes are activated by increased or coincident activity of these inputs. A similar role was assigned to the lamprey reticulospinal cells receiving sensory inputs from the trigeminal system ${ }^{43}$. This dual function of NVsnpr neurons is in line with their projections to the thalamus (sensory relay mode) and to brainstem motoneurons and premotor interneurons on one hand, and with their two firing modes on the other. Interestingly, the bursting frequency of NVsnpr neurons reported during fictive mastication in rabbit $(\sim 3 \mathrm{~Hz})^{44}$ corresponded to the chewing frequency in that species. Similarly, the frequency of bursting elicited here in the interface chamber whether by sensory stimulation, NMDA or $S 100 \beta$ corresponds to the chewing frequency observed in vivo in rats ${ }^{13}$. In submerged preparations, the bursting frequency was slower, but this probably results from differences in temperature between the two recordings conditions (room temperature for submerged vs $30-32^{\circ} \mathrm{C}$ for interface). 


\section{Implications for health and pathology}

Astrocytes have been shown to play a role in a number of important functions and in at least one rhythmic circuit, the respiratory CPG, where they alter the inspiratory rhythm by releasing $A \mathrm{AP}^{6}$ in response to change in $\mathrm{pH}$. However, in this case, the mechanism involved is $\mathrm{pH}$ dependant and seems specific to the ventral brainstem respiratory area ${ }^{45}$, whereas the mechanism of action reported here may be of a much broader relevance given the widespread distribution of both $\mathrm{S} 100 \mathrm{\beta}$ and $\mathrm{I}_{\mathrm{NaP}} 4,8,9,11,17,18,30$.

$$
\text { Regulation of } \mathrm{I}_{\mathrm{NaP}} \text {-mediated bursting by }
$$
astrocytes may help understand appearance of bursting in normal and pathological conditions such as epileptic seizures where astrocytes are over activated ${ }^{46}$. Generation and propagation of seizures are generally attributed to spread of activity in excitatory feedback circuits. However, surprisingly "in situ" measurements with ion-selective electrodes show that during seizures, $\left[\mathrm{Ca}^{2+}\right]_{e}$ drops to levels incompatible with chemical synaptic transmission ${ }^{47}$. Our results may help understand this paradoxical finding and could explain how bursting activity is maintained in absence of chemical synaptic transmission. These findings could help develop new targets and strategies for treatment of these conditions.

\section{ACKNOWLEDGMENTS}

This paper is dedicated to Laurent Vinay whose premature loss leaves us with a tremendous void. To a great man who left his mark in this field by his science and his humanity. We are extremely grateful to David Weber and Paul Wilder from the Center for Biomolecular Therapeutics for generously providing the mutated S100 $\beta$, which was well characterized in their previous work. We are equally grateful to James G. Omichinski for giving us access to his Microcal ITC-200 microcalorimeter and for counselling us with these experiments. We also thank Aude Panatier for counseling and assistance in several experiments on astrocytes, and Florin Amzica who guided us for the ion-sensitive recordings. Steven Condamine generously performed the immunostaining of $S 100 \beta$ in NVsnpr. Philippe Morquette received a fellowship from the Network for Oral Health and Bone Health research of the Fonds de Recherche Québec-Santé. This research was financed by a grant from the Canadian Institutes for Health Research (grant \#14392)

\section{AUTHOR CONTRIBUTIONS}

The work presented here was carried out in collaboration between all authors. All authors have contributed to, seen and approved the manuscript. A.K* and R.R co-supervised the project, worked together to define the research themes, design the experiments and draft the manuscript (writing and critical revision). P. M. co-designed and carried out the patch recording and $\mathrm{Ca}^{2+}$ - imaging experiments and worked on the data analysis, the interpretation of the results, and the drafting of the manuscript (writing and figures conception). D. V. co-designed and carried out part of the patch recording experiments, co-designed and carried out the interface configuration experiments and worked on the data analysis, interpretation of the results, and drafting of the manuscript (writing and figures conception). A. K. co-designed and carried out the calcium-ion sensitive recording experiments and worked on the data analysis, the interpretation of the results, and the drafting of the manuscript (writing and figures concepts). J.F. synthesized the S100 $\beta$ and conducted the microcalorimetry experiments and analyzed the related data. A.G.P. carried out some of the patch experiments and worked on the data analysis.

\section{COMPETING FINANCIAL INTERESTS}

The authors declare no competing financial interests. 


\section{REFERENCES LIST}

Grillner, S. Locomotion in vertebrates: central mechanisms and reflex interaction. Physiol Rev. 55, 247-304 (1975). Dellow, P. G. \& Lund, J. P. Evidence for central timing of rhythmical mastication. The Journal of physiology 215, 113 (1971).

Smith, J. C., Ellenberger, H. H., Ballanyi, K., Richter, D. W. \& Feldman, J. L. Pre-Botzinger complex: a brainstem region that may generate respiratory rhythm in mammals. Science 254, 726-729 (1991).

Harris-Warrick, R. M. General principles of rhythmogenesis in central pattern generator networks. Progress in brain research 187, 213-222, doi:10.1016/B978-0-444-53613-6.00014-9 (2010).

Del Negro, C. A. et al. Synaptically activated burst-generating conductances may underlie a group-pacemaker mechanism for respiratory rhythm generation in mammals. Progress in brain research 187, 111-136, doi:10.1016/B978-0-444-53613-6.00008-3 (2010).

Gourine, A. V. et al. Astrocytes control breathing through pH-dependent release of ATP. Science 329, 571-575, doi:10.1126/science.1190721 (2010).

Okada, Y. et al. Preinspiratory calcium rise in putative pre-Botzinger complex astrocytes. The Journal of physiology 590, 4933-4944, doi:10.1113/jphysiol.2012.231464 (2012).

Tazerart, S., Vinay, L. \& Brocard, F. The persistent sodium current generates pacemaker activities in the central pattern generator for locomotion and regulates the locomotor rhythm. J.Neurosci. 28, 8577-8589, doi:28/34/8577 [pii];10.1523/JNEUROSCI.1437-08.2008 [doi] (2008).

Brocard, F., Verdier, D., Arsenault, I., Lund, J. P. \& Kolta, A. Emergence of intrinsic bursting in trigeminal sensory neurons parallels the acquisition of mastication in weanling rats. J.Neurophysiol. 96, 2410-2424, doi:00352.2006 [pii];10.1152/jn.00352.2006 [doi] (2006).

Massimini, M. \& Amzica, F. Extracellular calcium fluctuations and intracellular potentials in the cortex during the slow sleep oscillation. Journal of neurophysiology 85, 1346-1350 (2001).

1 Brocard, F. et al. Activity-dependent changes in extracellular $\mathrm{Ca} 2+$ and $\mathrm{K}+$ reveal pacemakers in the spinal locomotor-related network. Neuron 77, 1047-1054, doi:10.1016/j.neuron.2013.01.026 (2013).

2 Trulsson, M. \& Johansson, R. S. Orofacial mechanoreceptors in humans: encoding characteristics and responses during natural orofacial behaviors. Behavioural brain research 135, 27-33 (2002).

Westneat, M. W. \& Hall, W. G. Ontogeny of Feeding Motor Patterns in Infant Rats - an Electromyographic Analysis of Suckling and Chewing. Behav Neurosci 106, 539-554, doi:Doi 10.1037//0735-7044.106.3.539 (1992).

4 Bernier, A. P., Arsenault, I., Lund, J. P. \& Kolta, A. Effect of the stimulation of sensory inputs on the firing of neurons of the trigeminal main sensory nucleus in the rat. Journal of neurophysiology 103, 915-923, doi:10.1152/jn.91109.2008 (2010).

Crill, W. E. Persistent sodium current in mammalian central neurons. Annual review of physiology 58, 349-362, doi:10.1146/annurev.ph.58.030196.002025 (1996).

Jones, H. C. \& Keep, R. F. Brain fluid calcium concentration and response to acute hypercalcaemia during development in the rat. The Journal of physiology 402, 579-593 (1988).

Li, Z. \& Hatton, G. I. Oscillatory bursting of phasically firing rat supraoptic neurones in low-Ca2+ medium: $\mathrm{Na}+$ influx, cytosolic Ca2+ and gap junctions. The Journal of physiology 496 ( Pt 2), 379-394 (1996).

$\mathrm{Su}, \mathrm{H}$., Alroy, G., Kirson, E. D. \& Yaari, Y. Extracellular calcium modulates persistent sodium current-dependent burst-firing in hippocampal pyramidal neurons. The Journal of neuroscience : the official journal of the Society for Neuroscience 21, 4173-4182 (2001).

Torres, A. et al. Extracellular Ca2+ Acts as a Mediator of Communication from Neurons to Glia. Sci Signal 5 (2012).

Wang, F. et al. Astrocytes modulate neural network activity by $\mathrm{Ca}(2)+-$ dependent uptake of extracellular K+. Sci Signal 5, ra26, doi:10.1126/scisignal.2002334 (2012).

Lazarov, N. E. Comparative analysis of the chemical neuroanatomy of the mammalian trigeminal ganglion and mesencephalic trigeminal nucleus. Progress in neurobiology 66, 19-59 (2002).

Serrano, A., Haddjeri, N., Lacaille, J. C. \& Robitaille, R. GABAergic network activation of glial cells underlies hippocampal heterosynaptic depression. The Journal of neuroscience : the official journal of the Society for Neuroscience 26, 5370-5382, doi:10.1523/JNEUROSCI.5255-05.2006 (2006).

Ciccarelli, R. et al. Activation of A(1) adenosine or mGlu3 metabotropic glutamate receptors enhances the release of nerve growth factor and S-100beta protein from cultured astrocytes. Glia 27, 275-281, doi:10.1002/(SICI)10981136(199909)27:3<275::AID-GLIA9>3.0.CO;2-0 [pii] (1999). 
Sakatani, S. et al. Neural-activity-dependent release of S100B from astrocytes enhances kainate-induced gamma oscillations in vivo. J.Neurosci. 28, 10928-10936, doi:28/43/10928 [pii];10.1523/JNEUROSCI.3693-08.2008 [doi] (2008). absence of a peptide derived from the C-terminal negative regulatory domain of p53. Biochemistry 44, 7305-7314, doi:10.1021/bi050321t (2005).

Egelman, D. M. \& Montague, P. R. Calcium dynamics in the extracellular space of mammalian neural tissue. Biophysical journal 76, 1856-1867 (1999).

Lian, X. Y. \& Stringer, J. L. Astrocytes contribute to regulation of extracellular calcium and potassium in the rat cerebral cortex during spreading depression. Brain research 1012, 177-184, doi:10.1016/j.brainres.2004.04.011 (2004).

Nicholson, C., Bruggencate, G. T., Steinberg, R. \& Stockle, H. Calcium modulation in brain extracellular microenvironment demonstrated with ion-selective micropipette. Proceedings of the National Academy of Sciences of the United States of America 74, 1287-1290 (1977). Jefferys, J. G. \& Haas, H. L. Synchronized bursting of CA1 hippocampal pyramidal cells in the absence of synaptic transmission. Nature 300, 448-450 (1982).

30 Del Negro, C. A., Morgado-Valle, C. \& Feldman, J. L. Respiratory rhythm: an emergent network property? Neuron 34, 821-830 (2002).

31 Armstrong, C. M. Distinguishing surface effects of calcium ion from pore-occupancy effects in Na+ channels. Proceedings of the National Academy of Sciences of the United States of America 96, 4158-4163 (1999). Rybak, I. A., Shevtsova, N. A., St-John, W. M., Paton, J. F. \& Pierrefiche, O. Endogenous rhythm generation in the pre-Botzinger complex and ionic currents: modelling and in vitro studies. The European journal of neuroscience 18, 239-257 (2003).

Tsuruyama, K., Hsiao, C. F. \& Chandler, S. H. Participation of a persistent sodium current and calcium-activated nonspecific cationic current to burst generation in trigeminal principal sensory neurons. Journal of neurophysiology 110, 1903-1914, doi:10.1152/jn.00410.2013 (2013). 798, doi:10.1016/j.cell.2011.07.022 (2011).

Pasti, L., Volterra, A., Pozzan, T. \& Carmignoto, G. Intracellular calcium oscillations in astrocytes: a highly plastic, bidirectional form of communication between neurons and astrocytes in situ. The Journal of neuroscience : the official journal of the Society for Neuroscience 17, 7817-7830 (1997).

Lee, M. C. et al. Characterisation of the expression of NMDA receptors in human astrocytes. PLoS.One. 5, doi:10.1371/journal.pone.0014123 [doi] (2010).

Sigvardt, K. A., Grillner, S., Wallen, P. \& Van Dongen, P. A. Activation of NMDA receptors elicits fictive locomotion and bistable membrane properties in the lamprey spinal cord. Brain research 336, 390-395 (1985).

Kim, Y. I. \& Chandler, S. H. NMDA-induced burst discharge in guinea pig trigeminal motoneurons in vitro. Journal of neurophysiology 74, 334-346 (1995).

39 Donato, R. et al. S100B's double life: intracellular regulator and extracellular signal. Biochimica et biophysica acta 1793, 1008-1022, doi:10.1016/j.bbamcr.2008.11.009 (2009).

40 Capra, N. F. \& Dessem, D. Central connections of trigeminal primary afferent neurons: topographical and functional considerations. Critical reviews in oral biology and medicine : an official publication of the American Association of Oral Biologists 4, 1-52 (1992).

41 Yamamura, K. et al. Effects of reversible bilateral inactivation of face primary motor cortex on mastication and swallowing. Brain research 944, 40-55 (2002).

42 Lund, J. P. \& Dellow, P. G. The influence of interactive stimuli on rhythmical masticatory movements in rabbits. Archives of oral biology 16, 215-223 (1971).

43 Di Prisco, G. V., Pearlstein, E., Robitaille, R. \& Dubuc, R. Role of sensory-evoked NMDA plateau potentials in the initiation of locomotion. Science 278, 1122-1125 (1997).

44 Tsuboi, A., Kolta, A., Chen, C. C. \& Lund, J. P. Neurons of the trigeminal main sensory nucleus participate in the generation of rhythmic motor patterns. The European journal of neuroscience 17, 229-238 (2003). regional specialization of astroglia. The Journal of neuroscience : the official journal of the Society for Neuroscience 33, 435-441, doi:10.1523/JNEUROSCI.2813-12.2013 (2013). 
Nature Neuroscience 18 : 844-854 / doi:10.1038/nn.4013

46 Gomez-Gonzalo, M. et al. An excitatory loop with astrocytes contributes to drive neurons to seizure threshold. PLoS.Biol. 8, e1000352, doi:10.1371/journal.pbio.1000352 [doi] (2010).

47 Pumain, R., Menini, C., Heinemann, U., Louvel, J. \& Silva-Barrat, C. Chemical synaptic transmission is not necessary for epileptic seizures to persist in the baboon Papio papio. Experimental neurology 89, 250-258 (1985).

48 Kafitz, K. W., Meier, S. D., Stephan, J. \& Rose, C. R. Developmental profile and properties of sulforhodamine 101-Labeled glial cells in acute brain slices of rat hippocampus. J Neurosci Methods 169, 84-92, doi:10.1016/j.jneumeth.2007.11.022 (2008). 


\section{ONLINE METHODS}

All procedures abode by the Canadian Institutes of Health Research rules and were approved by the University of Montreal Animal Care and Use Committee.

\section{Brainstem slice preparations}

Experiments were conducted on 15-21 day old Sprague-Dawley rats anesthetized with isoflurane (Pharmaceutical Partners of Canada Inc., Richmond Hill, Ontario, Canada) prior to decapitation. Their brain was quickly removed from the cranium and dipped in an ice cold sucrose-based solution containing (in mM): $3 \mathrm{KCl}, 1.25 \mathrm{KH}_{2} \mathrm{PO}_{4}, 4 \mathrm{MgSO}_{4}, 26 \mathrm{NaHCO}_{3}, 10 \mathrm{Dextrose}$ $0.2 \mathrm{CaCl}_{2}, 219$ Sucrose and bubbled with a mix of $95 \% \mathrm{O}_{2}$ and $5 \% \mathrm{CO}_{2}, \mathrm{pH} 7.3-7.4,300-320 \mathrm{mOsmol} / \mathrm{kg}$. Transverse slices (300-400 $\mathrm{mm}$ thick) of the trigeminal main sensory nucleus (NVsnpr) were prepared in the same medium with a Vibratome (Leica, Model VT 100S). Slices were then stored and allowed to rest for an hour in a holding chamber filled with artificial cerebro-spinal fluid at room temperature (aCSF; 95\% $\mathrm{O}_{2}+5 \% \mathrm{CO}_{2}$ ). The aCSF contained (in $\mathrm{mM}$ ): $124 \mathrm{NaCl}, 3 \mathrm{KCl}, 1.25$ $\mathrm{KH}_{2} \mathrm{PO}_{4}, 1.3 \mathrm{MgSO}_{4}, 26 \mathrm{NaHCO}_{3}, 10$ Dextrose and $1.6 \mathrm{CaCl}_{2}, \mathrm{pH} 7.3-7.4,290-300 \mathrm{mOsmol} / \mathrm{kg}$. This composition of aCSF was used in all experiments throughout the study, except in experiments conducted to isolate $\mathrm{I}_{\mathrm{NaP}}$ in voltage clamp (see below) and experiments where the $\mathrm{CaCl}_{2}$ was either increased to $2.6 \mathrm{mM}$ or omitted and replaced by $\mathrm{MgCl}_{2}(1.6 \mathrm{mM})$. The experiments where such manipulations of the $\left[\mathrm{Ca}^{2+}\right]$ were used are clearly stated in the results.

\section{Electrophysiological recordings}

\section{-Interface configuration}

For experiments done in the interface chamber configuration, $400 \mu \mathrm{m}$ thick slices were kept at $30-32^{\circ} \mathrm{C}$ at the interface between a warm humidified atmosphere of $95 \% \mathrm{O}_{2} / 5 \% \mathrm{CO}_{2}$ and aCSF. NVsnpr was identified under $4 \mathrm{X}$ magnification and field potential, extracellular recording electrodes as well as calcium-sensitive electrodes (see details below) were placed in the dorsal part of the nucleus and connected through their own amplifiers to a Micro 1401 mk II acquisition unit (Cambridge Electronic Design, Cambridge, UK). All electrodes, except for the calcium-sensitive one were filled with $\mathrm{NaCl}$ (0.5 M). An Isostim stimulator (model A320; WPI, Sarasota, FL, USA) and tungsten (unipolar) or nichrome (bipolar) electrodes were used to electrically stimulate $(40-60 \mathrm{~Hz})$ the sensory fibers in the trigeminal tract projecting to NVsnpr.

\section{-Submerged configuration}

Whole cell experiments and calcium imaging recordings were conducted at room temperature in an immersion chamber using 300-350 $\mu \mathrm{m}$ thick slices. Neurons and astrocytes were visualized with an infrared-sensitive CCD camera and displayed on a video monitor. The camera was mounted on an Olympus FluoView FV 1000 confocal microscope equipped with a $40 \mathrm{X}$ water-immersion objective. Whole cell recordings were performed in the current clamp mode or in the voltage clamp mode (see below) using a computer-controlled Multiclamp 700A amplifier and a Digidata 1322A digitizer (Axon Instruments, Downingtown, PA, USA). The setup was equipped with two headstages allowing recordings of pairs of cells. Patch pipettes were pulled from borosilicate glass capillaries (1.5 mm OD, $1.12 \mathrm{~mm}$ ID; World Precision Instruments, Sarasota, FL) on a Sutter P-97 puller (Sutter Instruments, Novato, CA). Electrodes for neuronal recordings (resistance 7-10 M $\Omega$ ) were filled with (in mM): $140 \mathrm{~K}$-gluconate, $5 \mathrm{NaCl}, 2 \mathrm{MgCl}_{2}, 10$ HEPES, 0.5 EGTA, Tris 2 ATP salt, Tris 0.4 GTP salt, pH 7.2-7.3, 280-300 $\mathrm{mOsmol} / \mathrm{kg}$. After the establishment of gigaseal, the pipette resistance and capacitance were compensated electronically. Neurons were monitored all along experiments to assess their viability and were discarded when action potentials did not overshoot $0 \mathrm{mV}$ or when the resting membrane potential was depolarized ( $\geq-45 \mathrm{mV}$ ). Electrodes for astrocyte recordings (resistance 5-7 M $\Omega$ ) were filled with (in mM): $125 \mathrm{KMeSO}_{4}, 10 \mathrm{HEPES}, 4 \mathrm{MgCl}_{2}, 4 \mathrm{ATP}, 0.4 \mathrm{GTP}, 10 \mathrm{Na}_{2} \mathrm{CreatinePO}_{4}$ and 0.1 Alexa Fluor 488, pH 7.2-7.3, 295-300 mosmol/kg. For imaging experiments in single astrocytes, the $\mathrm{Ca}^{2+}$-indicator fluo-4 $(100 \mu \mathrm{M})$ (Invitrogen) was added to the internal solution and Alexa Fluor 488 was omitted. Astrocytes were identified on the basis of their small size $(\sim 10 \mu \mathrm{m})$ and characteristic morphology of round soma surrounded by many processes. In some experiments, sulforhodamine 101 (SR101, $1 \mu \mathrm{M}$ ) was used as a specific marker of astrocytes following the procedure of Kafitz et al. $^{48}$. Astrocytes were also systematically characterized by performing a whole-cell current-voltage profile with a ramp voltage command from -130 to $+110 \mathrm{mV}$ (586 ms duration) and also injection of step current to confirm their characteristic passive membrane. Astrocytes with resting membrane potentials more depolarized than $-60 \mathrm{mV}$ were rejected. In some experiments, BAPTA (1,2-Bis(o-AminoPhenoxy)ethane-N,N,N',N'-Tetraacetic Acid, tetrapotassium salt, 0.1 
or 10-35 mM) was added to the internal solution and KMeSO4 or K-gluconate concentration was adjusted accordingly to maintain potassium ions concentration.

\section{-Voltage-clamp experiments}

Whole cell voltage clamp recordings were carried in presence of several blockers in order to assess the effects Ca ${ }^{2+}$, extracellular BAPTA and $\mathrm{S} 100 \beta$ on pharmacologically isolated $\mathrm{Na}^{+}$currents. The modified aCSF used contained in mM: 131 $\mathrm{NaCl}, 10 \mathrm{HEPES}, 3 \mathrm{KCl}, 10$ glucose, $2 \mathrm{CaCl}_{2}, 2 \mathrm{MgCl}_{2}, 10$ tetraethylammonium (TEA)-Cl, $10 \mathrm{CsCl}, 1$ 4-aminopyridine (4-AP), and $0.3 \mathrm{CdCl}_{2}$. The electrodes were filled with a solution containing in mM: $130 \mathrm{CsF}, 9 \mathrm{NaCl}, 10 \mathrm{HEPES}_{10} 10 \mathrm{EGTA}, 1 \mathrm{MgCl}, 3 \mathrm{~K}_{2}-$ ATP, and $1 \mathrm{Na}-\mathrm{GTP}$. The $\mathrm{pH}$ and the osmolarity were adjusted to 7.2-7.3 and 280-290 mOsm respectively. All current traces were leak substracted and $I_{\mathrm{NaP}}$ current was revealed by substraction of the currents remaining in riluzole or TTX.

\section{Calcium-sensitive electrodes}

Electrodes were made of borosilicate glass pretreated with dimethylchlorosilane and dried at $120{ }^{\circ} \mathrm{C}$ for two hours. The tip of the pipette was filled with calcium ionophore I - cocktail A (Sigma-Aldrich, St Louis, Missouri, USA). The rest of the electrode was filled with $\mathrm{CaCl}_{2}(2 \mathrm{M})$. Prior to recordings, the electrode was calibrated with aCSF solutions containing increasing concentrations of calcium $(0,0.4,0.8,1.2,1.6$ and $2 \mathrm{mM})$ and the potential jump for each concentration was recorded. The calibration curve obtained from these data was best fitted with a logarithmic function. Only electrodes exhibiting a potential jump higher than $20 \mathrm{mV}$ (mean $=26.96 \pm 1.82 \mathrm{mV}, n=13$ ) per decade (i.e. between concentrations 0.2 and $2 \mathrm{mM}$ ) were kept for our experiments.

\section{$\mathrm{Ca}^{2+}$-imaging}

Confocal imaging was performed using an Olympus FluoView FV 1000 confocal microscope equipped with a 40X waterimmersion lens (Olympus, 0.80 N.A.). The $559 \mathrm{~nm}$ diode laser line was used to excite SR101 and the emitted fluorescence was detected through a band pass filter 570-640 $\mathrm{nm}$. $\mathrm{Ca}^{2+}$ indicators (fluo-4, fluo4-AM or fluo8L-AM) and Alexa Fluor 488 were excited with an argon laser line (488 $\mathrm{nm}$ ) and emission was detected through a band pass filter (500-545 $\mathrm{nm}$ ). For $\mathrm{Ca}^{2+}$-imaging in single cells, the $\mathrm{Ca}^{2+}$-indicator fluo-4 $(100 \mu \mathrm{M}$, Invitrogen, Grand Island, NY, USA) was added to the internal solution of the recorded cell, while for $\mathrm{Ca}^{2+}$-imaging in a population of cells, the slices were incubated for 45-60 min with the cell-permeant $\mathrm{Ca}^{2+}$ indicators fluo4-AM $(20 \mu \mathrm{M}$, Invitrogen, Grand Island, NY, USA) or fluo8L-AM (20 $\mu$ M, AAT Bioquest, Inc, Sunnyvale, CA, USA) and 0.5\% dimethylsulfoxide (DMSO) at room temperature in oxygenated ACSF. Slices were allowed to rest for 30 minutes before sequence acquisition. Images were acquired at $0.429 \mathrm{~s}$ per frame. Offline analysis of sequences was performed with ImageJ software ( $\mathrm{NIH}$, USA). Fluorescence intensity was determined on each individual cell by measuring the average pixel values in defined regions of interest (ROI) on each frame of the sequence. ROI were placed either on the somata (for AM loading) or on the processes (intra-loading experiment). Changes in fluorescence $(\Delta \mathrm{F})$, are presented as relative changes in fluorescence intensity from baseline and expressed as $(\% \Delta F / F 0)=[(F-F 0) / F 0] \times 100, F 0$ being the fluorescence baseline. Because responses were collected over extended periods of time and after repeated NMDA applications, only robust changes of more than $25 \%$ were included in the analysis.

\section{Drugs}

The following drugs were locally applied near the recorded cells using positive pressure pulses (Picospritzer III) to one or two pipettes containing either: N-Methyl-D-Aspartate (NMDA, 1-2 mM,), 1,2-bis(2-Aminophenoxy)ethane-N,N,N',N'tetraacetic acid tetrasodium salt (BAPTA tetrasodic salt, 10mM), glutamate (1 mM). In some experiments, MK-801 (2 mM) and BAPTA tetrapotassium salt $(0.1,10-35 \mathrm{mM})$ were added to the internal solution of the recording electrode. The following drugs were bath applied: Tetrodotoxin (TTX, 1-2 $\mu \mathrm{M})$, riluzole $(20 \mu \mathrm{M})$, Suramine $(50 \mu \mathrm{M})$, CNQX (10 $\mu \mathrm{M}$, Cadmium (100 $\mu \mathrm{M}$, and L-trans-pyrollidine-2,4-dicarboxylic acid (PDC) (50 $\mu \mathrm{M})$. Compounds were purchased from SigmaAldrich (Oakville, Ontario, Canada), Tocris Bioscience (Ellisville, Missouri, USA), and Invitrogen (Grand Island, New York, USA).

Antibodies used to pretreat the tissue in some experiments were applied with a large tip pipette that was lowered on the surface of the tissue near the neuronal and ion-sensitive recording electrodes. The antibody containing pipette was left there to leak for 10-15 min prior to testing the effects of the antibody. Sometimes a small pressure was applied to eject the antibody from the pipette. Two antibodies were tested: anti-S100 $\beta$ antibody $(40 \mu \mathrm{g} / \mathrm{ml}$, sodium azide salt (140 
$\mu \mathrm{M})$; Sigma Aldrich, \# S2532) or non-specific donkey anti-sheep antibody (120 $\mathrm{gg} / \mathrm{ml}$, sodium azide salt (312 $\mu \mathrm{M})$; Invitrogen-Molecular Probes, \# A11015),

S100 $\beta$ was synthesized at the Recombinant Proteins and Antibodies Facility of the Institute for Research in Immunology and Cancer of the University of Montreal. A cDNA corresponding to mouse S100 $\beta$ was sub-cloned in pETM14 expression vector harboring a N-terminal hexa-Histidine tag and a precision cleavage site. The resulting vector was used to transform BL21 E. coli cells for protein expression in "terrific broth" medium supplemented with $1 \% \mathrm{glucose}$ and $50 \mu \mathrm{g} / \mathrm{ml}$ kanamycin. Cells were grown at $37^{\circ} \mathrm{C}$ with vigorous shaking. When the culture reached an OD600 of 0.8 , temperature was reduced to $18^{\circ} \mathrm{C}$, and expression was induced with $0.5 \mathrm{mM}$ IPTG for 16 hours. Cells were then harvested by centrifugation and resuspended in lysis buffer (Tris- $\mathrm{HCl} 50 \mathrm{mM} \mathrm{pH} \mathrm{8,} \mathrm{NaCl} 500 \mathrm{mM}, \mathrm{BME} 5 \mathrm{mM}, \mathrm{PMSF} 1 \mathrm{mM}$, and one tablet/100ml of complete EDTA-free protease inhibitors). After 2 cycles of freeze-thaw, cells were sonicated and centrifuged for $1 \mathrm{~h}$ at 45 $000 \mathrm{x}$ g. Recombinant protein in the supernatant was purified by metal affinity chromatography on a POROS-MC20 perfusion chromatography column (with $\mathrm{Ni}^{2+}$ as the chelating metal), preequilibrated in Tris- $\mathrm{HCl} 50 \mathrm{mM} \mathrm{pH} 8, \mathrm{NaCl} 500 \mathrm{mM}$, BME $5 \mathrm{mM}$, PMSF 1mM and EDTA-free protease inhibitor tablet. After extensive washing of the column, bound proteins were eluted with a gradient of imidazole $(0-500 \mathrm{mM})$ in Tris- $\mathrm{HCl} 50 \mathrm{mM} \mathrm{pH} 8$ and $\mathrm{NaCl} 150 \mathrm{mM}$. Fractions were analyzed by SDS-PAGE and positive ones were pooled, and further purified on a preparative scale high-resolution Superdex-200 gel filtration column equilibrated in HEPES $20 \mathrm{mM} \mathrm{pH} \mathrm{7.4,} \mathrm{NaCl} 150 \mathrm{mM}, \mathrm{BME} 5 \mathrm{mM}$ and protease inhibitors. Fractions containing recombinant $\mathrm{S} 100 \beta$ were pooled and concentrated by ultrafiltration on Amicon Ultra YM-30 membranes to a concentration of $14.0 \mathrm{mg} / \mathrm{ml}$, supplemented with glycerol to a final concentration of $50 \%$, aliquoted and flash frozen in liquid nitrogen before storing at $-80^{\circ} \mathrm{C}$. Before use, to eliminate the glycerol, aliquots of the protein were thawed and microdialysed overnight using a dialysis device (Float-A-Lyzer from Spectra/Por) floating in a 20 mM Hepes buffer containing $140 \mathrm{mM}$ of $\mathrm{NaCl}$ at $\mathrm{pH}$ 7.4. The protein was then reconcentrated by centrifugation using centrifugal filter units (Amicon Ultra). The same buffer (20 mM Hepes containing $140 \mathrm{mM} \mathrm{NaCl}$, but no $\mathrm{Ca}^{2+}$ ) was used to suspend and adjust its concentration to either $129 \mu \mathrm{M}$ for its local application in the submerged chamber or $50 \mu \mathrm{M}$ for its local application in the interface chamber. In a second set of experiments, $1.6 \mathrm{mM} \mathrm{CaCl}_{2}$ was added to the buffer used to suspend $\mathrm{S} 100 \beta$ and the protein was tested at 2 concentrations in this buffer ( $129 \mu \mathrm{M}$ and $1 \mathrm{mM})$.

The mutated $\mathrm{S} 100 \beta$ protein was obtained from Dr D. Weber from the Center for Biomolecular Therapeutics, University of Maryland School of Medicine. It was synthesized using similar methods as above, but had two mutated residues, E31A and E72A, in both the pseudo- and typical EF-hand domains. This mutated protein was characterized using Nuclear Magnetic Resonance (NMR), stopped-flow kinetics, and thermodynamic binding methods (Isothermal titration calorimetry) and shown to have very weak, if any, binding to $\mathrm{Ca}^{2+}$, even at concentrations greater than $20 \mathrm{mM} \mathrm{M}^{25}$. The mutated protein was also suspended in a $20 \mathrm{mM}$ Hepes buffer containing $140 \mathrm{mM} \mathrm{NaCl}$, and $1.6 \mathrm{mM} \mathrm{CaCl}_{2}$ and locally applied at a concentration of $1 \mathrm{mM}$.

\section{Isothermal titration calorimetry}

The apparent dissociation constant (KD) for calcium binding to recombinant S100 $\beta$ and the effect of anti-S100 $\beta$ monoclonal antibody on calcium binding of $S 100 \beta$ was measured by Isothermal Titration Calorimetry (ITC) at $20^{\circ} \mathrm{C}$ using a Microcal ITC200 microcalorimeter (GE Healthcare ). The recombinant protein was dialyzed extensively against $20 \mathrm{mM}$ Hepes, $\mathrm{pH} 7.4$ containing $20 \mathrm{mM} \mathrm{NaCl}$, and $\mathrm{CaCl}_{2}$ was added to $2 \mathrm{mM}$ in the resulting dialysis buffer. $\mathrm{S} 100 \beta$ at a concentration of $25 \mu \mathrm{M}$ in the reservoir was titrated with 16 injections of $2.5 \mu \mathrm{CaCl}_{2}$. In order to verify the effect of antibody binding on $\mathrm{S} 100 \beta$ calcium binding capacity, a pre-formed complex of $25 \mu \mathrm{M} \mathrm{S} 100 \beta$ and $50 \mu \mathrm{M}$ monoclonal S100 $\beta$ antibody was dialyzed against the same buffer, and titrated with $2 \mathrm{mM} \mathrm{CaCl}_{2}$. The resulting thermograms for both experiments were analyzed with the ORIGIN 7 software.

\section{Analysis of firing patterns}

Firing patterns were characterized as tonic or rhythmic bursting discharge. As depicted in Supplementary Fig. 1, tonic discharge typically consisted of low frequency single spikes separated by regular, but relatively long, intervals (interspike intervals: ISI of 150-300 ms). In intracellular recordings these intervals appeared as afterhyperpolarizations. In transition between tonic and burst firing, the afterhyperpolarization gradually reverted into an afterdepolarization which often gave rise to a $2^{\text {nd }}$ spike (Supplementary Fig. 1 middle panel) at a very short ISI. Although these doublets resembled burst firing, we used more stringent criteria for the latter by defining bursts as clusters of at least 3 action potentials occurring at high 
frequency $(>130 \mathrm{~Hz}$ ) followed by a long silent period. In intracellular records, bursts appeared as depolarizing plateaus overridden by at least 3 actions potentials. The period separating the beginning of two consecutive plateaus was used to calculate the inter-burst frequency in intracellular recordings, whereas in extracellular recordings, the period separating the first spike of two consecutive bursts was used for this measure. Bursting frequency was calculated only in neurons that displayed a stable rhythmic discharge for more than 5 cycles. In both types of recordings, the ISI of action potentials within a burst was used to calculate the intra-burst frequency.

\section{Immunohistochemistry}

Standard immunocytochemical procedures as reported in Panatier et al. (2011) $)^{34}$ were used for immunostainings of S100 $\beta$ in NVsnpr.

\section{Statistics}

Data are presented as mean \pm Standard Error (SE) throughout the text. No statistical methods were used to pre-determine sample sizes but our sample sizes are similar to those generally employed in the field. Since there was no a priopri treatment of the animals, no procedures were used for blinding or randomization. Parametric tests were used when data was distributed normally according to the Kolmogorov-Smirnov test. In that case, between groups comparisons were performed with ANOVAs and for pairwise comparisons, paired t-tests, independent t-tests or Tukey's tests were used. Otherwise, non-parametric tests were used. Groups were compared with Kruskal-Wallis and Dunn's post test for multiple comparisons, while Mann-Whitney test was used for pairwise comparisons. Probabilities of alpha-type errors of $<0.05$ were considered to be significant. 
Supplementary Table 1: Characteristics of burst firing.

\begin{tabular}{|c|c|c|c|c|c|c|}
\hline & \multicolumn{3}{|c|}{ Interface configuration } & \multicolumn{3}{|c|}{ Submerged configuration } \\
\hline & Electrical stim & NMDA & $S 100 \beta$ & $\mathrm{Ca}^{2+}$-free & NMDA & S100 $\beta$ \\
\hline $\begin{array}{c}\text { Inter-burst } \\
\text { frequency (Hz) }\end{array}$ & $\begin{array}{c}8.56 \pm 1.03 \\
(n=9)\end{array}$ & $\begin{array}{c}7.43 \pm 1.20 \\
(n=12)\end{array}$ & $\begin{array}{c}7.47 \pm 0.54 \\
(n=31)\end{array}$ & $\begin{array}{c}2.77 \pm 0.76 \\
(n=14)\end{array}$ & $\begin{array}{c}3.48 \pm 0.71 \\
(n=57)\end{array}$ & $\begin{array}{c}3.54 \pm 0.53 \\
(n=33)\end{array}$ \\
\hline $\begin{array}{c}\text { Intra-burst } \\
\text { frequency }(\mathrm{Hz})\end{array}$ & $\begin{array}{c}217.56 \pm 13.41 \\
(n=9)\end{array}$ & $\begin{array}{c}214.83 \pm 24.14 \\
(n=12)\end{array}$ & $\begin{array}{c}286.87 \pm 17.71 \\
(n=31)\end{array}$ & $\begin{array}{c}152.88 \pm 15.72 \\
(n=12)\end{array}$ & $\begin{array}{c}172.44 \pm 9.78 \\
(n=52)\end{array}$ & $\begin{array}{c}217.97 \pm 13.27 * \\
(n=30)\end{array}$ \\
\hline $\begin{array}{l}\text { Frequency of tonic } \\
\text { discharge }(\mathrm{Hz})\end{array}$ & $\begin{array}{c}5.99 \pm 2.32 \\
(n=9)\end{array}$ & $\begin{array}{c}5.12 \pm 0.17 \\
(n=10)\end{array}$ & $\begin{array}{c}3.33 \pm 0.77 \\
(n=22)\end{array}$ & $\begin{array}{c}6.42 \pm 1.26 \\
(n=10)\end{array}$ & $\begin{array}{c}6.06 \pm 0.74 \\
(n=35)\end{array}$ & $\begin{array}{c}5.52 \pm 0.74 \\
(n=17)\end{array}$ \\
\hline $\begin{array}{l}\text { Vm burst } \\
(\mathrm{mV})\end{array}$ & - & - & - & $\begin{array}{c}-55.83 \pm 1.35 \\
(n=14)\end{array}$ & $\begin{array}{c}-60.66 \pm 0.78^{*} \\
(n=57)\end{array}$ & $\begin{array}{c}-58.27 \pm 0.97 \\
(n=33)\end{array}$ \\
\hline
\end{tabular}

Bursting frequency differed systematically between the submerged and the interface configurations (Mann-Whitney test; $P=<1 \mathrm{E}-10$ ), even when bursting was induced by the same substance. However, bursting obtained in each configuration with different drugs or procedures did not differ in frequency. For each condition, control tonic firing was obtained in $1.6 \mathrm{mM} \mathrm{Ca}^{2+}$ prior to the experimental condition. Some cells were silent at rest, discharged irregularly or had ripples instead of spikes on their plateaus. These were not included in the data analysis above. In all conditions, for the two configurations, the intra-burst frequency differed markedly from the frequency of tonic firing (Mann-Whitney test; $P=<1 \mathrm{E}-10$ ). In the submerged configuration, the intra-burst frequency obtained with S100 $\beta$ was significantly higher than with NMDA ( $n=12$ cells in 10 slices from 10 rats) and Ca ${ }^{2+}$ - free aCSF (Tukey's test $\left.P=0.02 ; * P<0.05\right)$. The potentials at which bursts first appeared (Vm burst) varied slightly across conditions, but differed significantly only between NMDA and $\mathrm{Ca}^{2+}$-free aCSF (Tukey's test $P=0.016 ;{ }^{*} P<0.05$ ). 
Nature Neuroscience 18 : 844-854 / doi:10.1038/nn.4013

INTRACELLULAR RECORDING

Tonic discharge

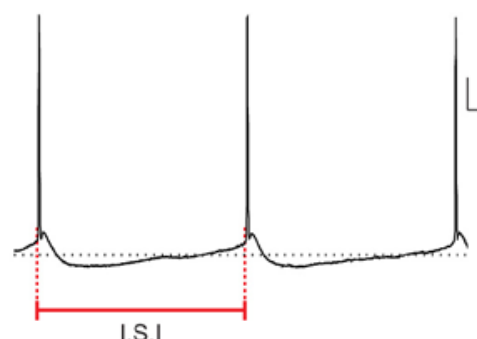

I.S.I

EXTRACELLULAR RECORDING

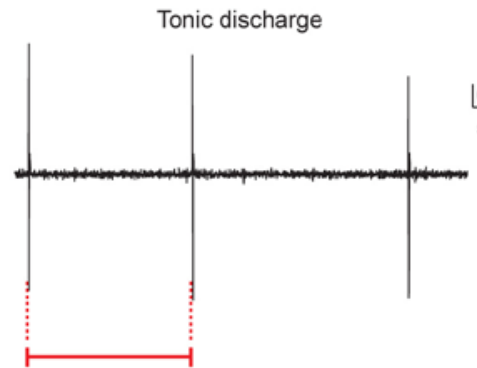

I.S.I
Doublets of spikes
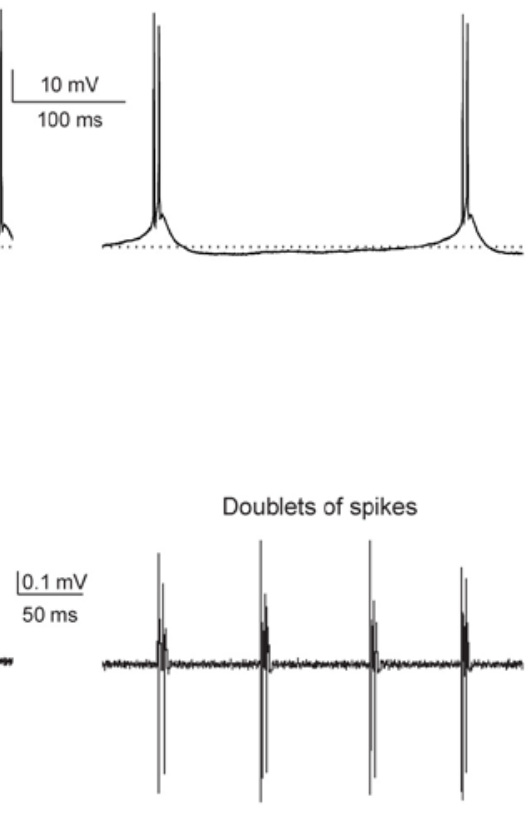

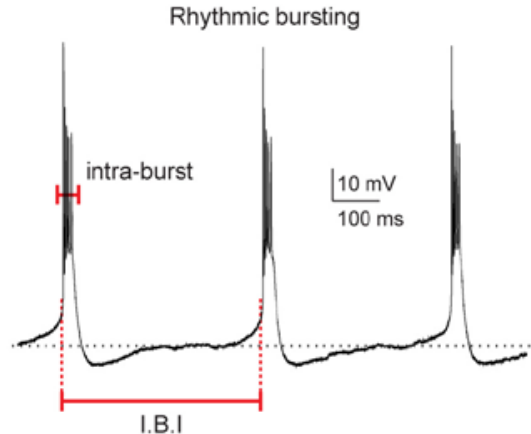

I.B.I

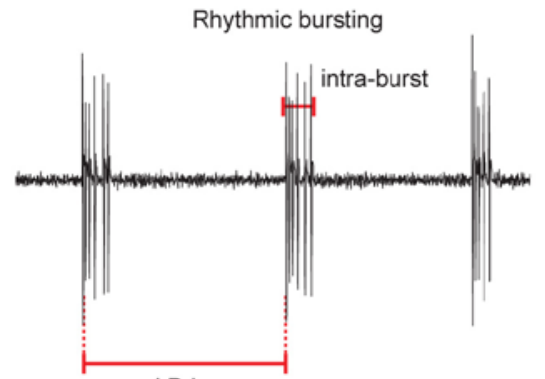

I.B.I

Supplementary Figure 1: Distinction between different firing patterns. Examples of whole cell recordings (top) and extracellular recordings (bottom) showing the regular low-frequency firing referred to as tonic firing (left) and the rhythmic bursting firing (right). Bursts are clusters of at least 3 spikes occurring at high frequency separated by silent periods. In whole cell rhythmic records, these spikes appeared on top of depolarizing plateaus. Doublets of spikes (middle), where an ADP following the first spike supports a second spike, are often recorded in transition between these two types of firing patterns. ISI $\neg=$ interspike interval; IBI = interburst interval. 
a

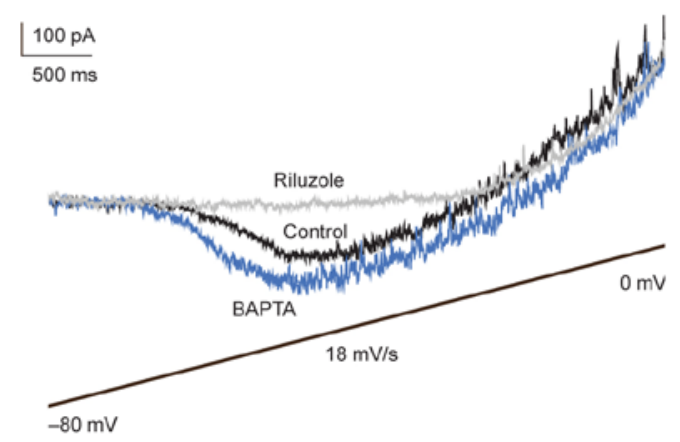

c

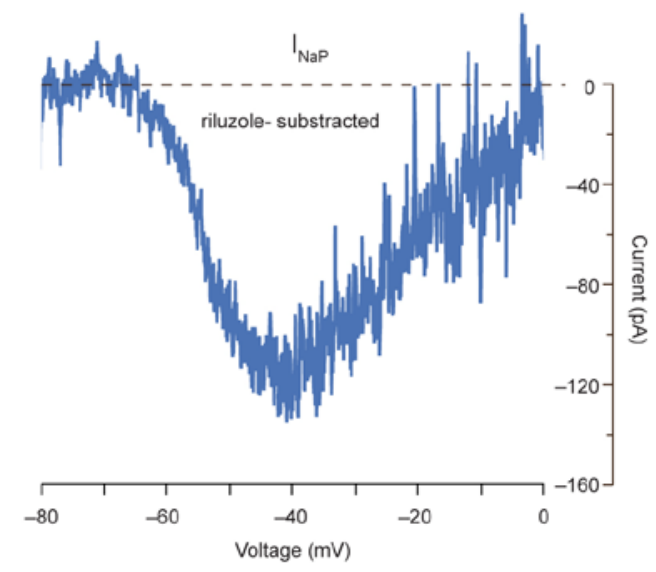

b

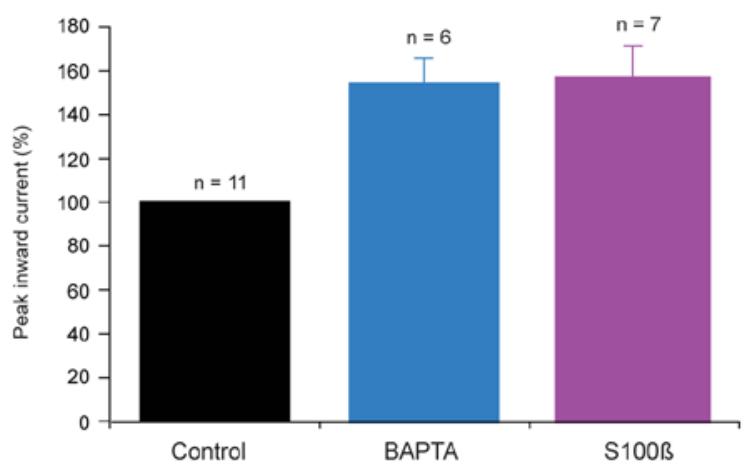

d

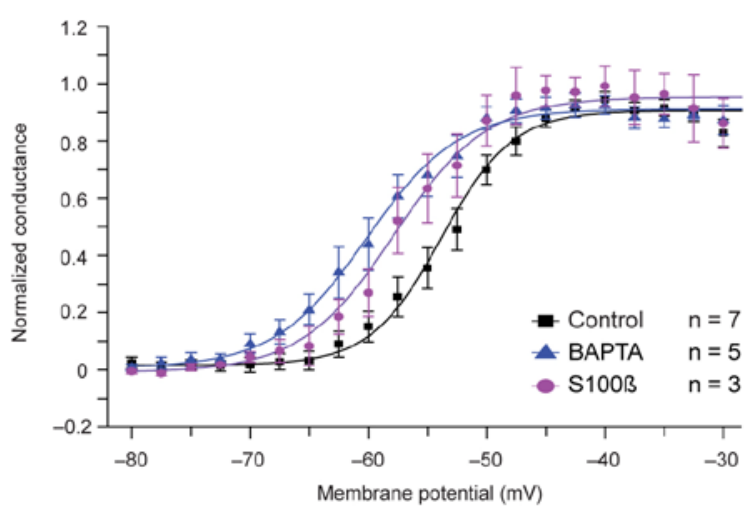

Supplementary Figure 2: Modulation of the pharmacologically-isolated $\mathrm{I}_{\mathrm{Nap}}$ by local applications of substances that reduce [Ca $\left.{ }^{2+}\right]_{\text {. }}$. (a) The inward current induced by voltage ramps from -80 to $0 \mathrm{mV}$ (lower trace), after leak subtraction, under control conditions (black) is enhanced during local application of BAPTA $(10 \mathrm{mM}$ ) (blue, $n=6$ cells in 4 slices from 4 rats, control: $126.69 \pm 40$ pA vs BAPTA: $188 \pm 54$ pA, paired t-test; $P=0.021$ ) and blocked by riluzole $(20 \mu \mathrm{M})$ (grey, $n=4$ cells in 4 slices from 3 rats). (b) The histograms illustrate the amplitude of the peak inward current during local application of BAPTA ( $n=6$ cells in 4 slices from 4 rats) and S100 $\beta(n=7$ cells in 5 slices from 5 rats) normalized to the control ( $n=11$ cells in 7 slices from 7 rats). (c) Pharmacologically-isolated trace of INaP obtained after subtracting the trace obtained with BAPTA and riluzole from the trace obtained with BAPTA alone (same cell as in (a)). (d) Voltage-dependency of $\mathrm{I}_{\mathrm{Na}}$ activation under control conditions (black) and during BAPTA (blue) and $\mathrm{S} 100 \beta$ (purple) application. $\mathrm{I}_{\mathrm{NaP}}$ was normalized to the maximal value and fitted with a single Boltzmann function. Controls: $\mathrm{V} 1 / 2 \mathrm{max}=-53.8 \pm 0.4$ $\mathrm{mV}$, slope factor of the fitted curve $\mathrm{k}=7.4$. BAPTA: $\mathrm{V} 1 / 2 \mathrm{max}=-60.2 \pm 0.5 \mathrm{mV}$ and $\mathrm{k}=5.8$. $\mathrm{S} 100 \mathrm{\beta}: \mathrm{V} 1 / 2 \mathrm{max}=-57.8 \pm 0.7 \mathrm{mV}$ and $\mathrm{k}=6.1$. Conductance was calculated with $\mathrm{G}=\mathrm{I} /(\mathrm{V}-$ Erev $)$. Erev $=-65 \mathrm{mV}$, based on the concentration of extracellular and intracellular pipette solutions. 
Control

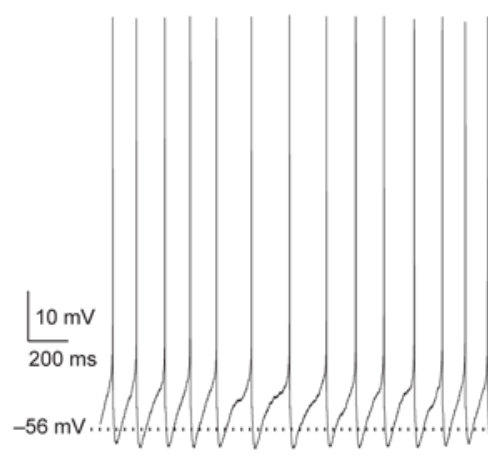

+Suramine

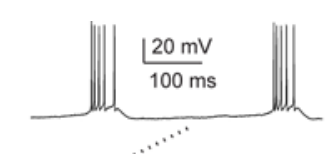

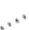
Supplementary Figure 3: Neuronal NVsnpr bursting does not depend on a purinergic mechanism. A tonically firing NVsnpr neuron (left)
displayed rhythmic bursting after local extracellular application of BAPTA (10 mM; right) in presence of bath-applied Suramine $(50 \mu \mathrm{M}, \mathrm{n}=5 / 5$ cells in 3 slices from 1 rat), a purinergic receptors antagonist, indicating that NVsnpr neuronal bursting does not depend on a purinergic mechanism triggered by the $\left[\mathrm{Ca}^{2+}\right]_{e}$ decrease. 
a

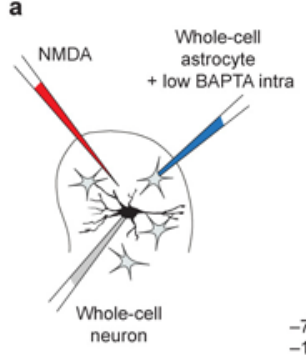

Control

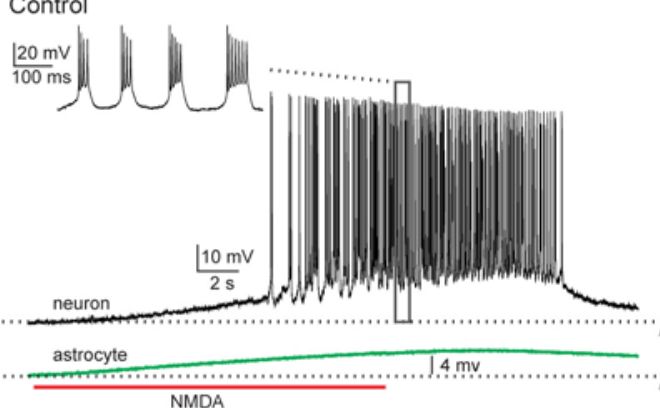

b $\mathrm{Ca}^{2 *}$ free

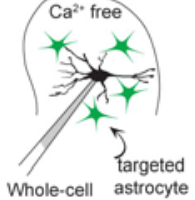

Whole-cell astrocyte

neuron

Control
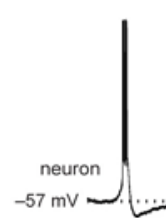

1 hour later

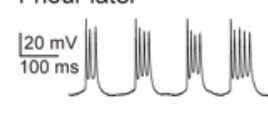

....

$-108 \mathrm{pA}$
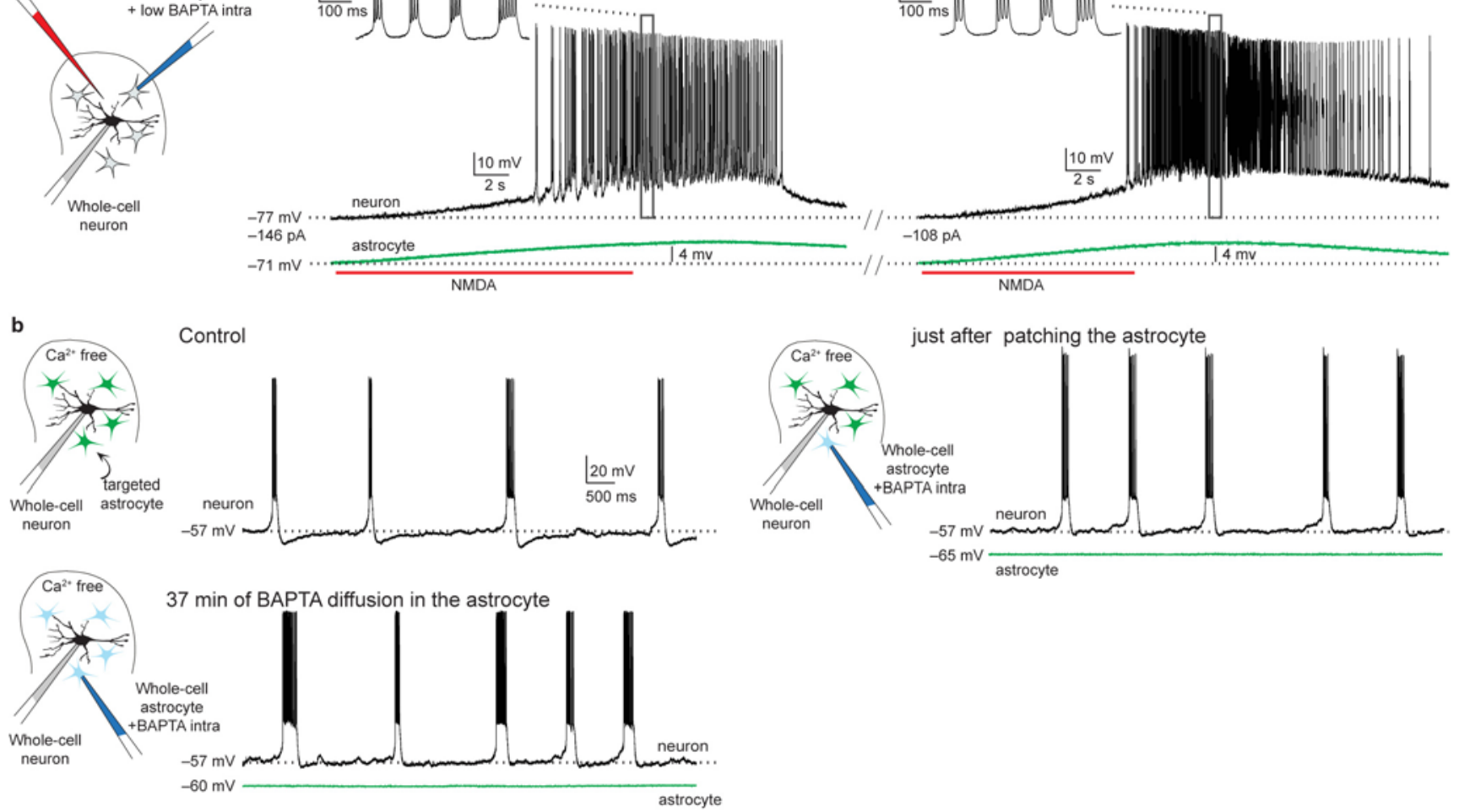

Supplementary Figure 4: The effects of diffusion of intracellular BAPTA in the astrocytic syncytium depend on the concentration of BAPTA used and are occluded in $\mathrm{Ca}^{2+}$-free aCSF. (a) Dialysis of an astrocyte with a low concentration of BAPTA (0.1 mM) does not prevent bursting in the adjacent neuron, even after one hour ( $n=4 / 4$ pairs in 4 slices from 4 rats). (b) Spontaneous rhythmic bursting of an NVsnpr neuron recorded in $\mathrm{Ca}^{2+}$-free aCSF (top left) persisted after dialysis of an adjacent astrocyte (green trace) with BAPTA (20 mM, bottom left, $n$ $=3$ pairs in 3 slices from 3 rats) consistent with an astrocytic regulation of neuronal bursting by decreasing $\left[\mathrm{Ca}^{2+}\right]_{e}$. 
Nature Neuroscience 18 : 844-854 / doi:10.1038/nn.4013

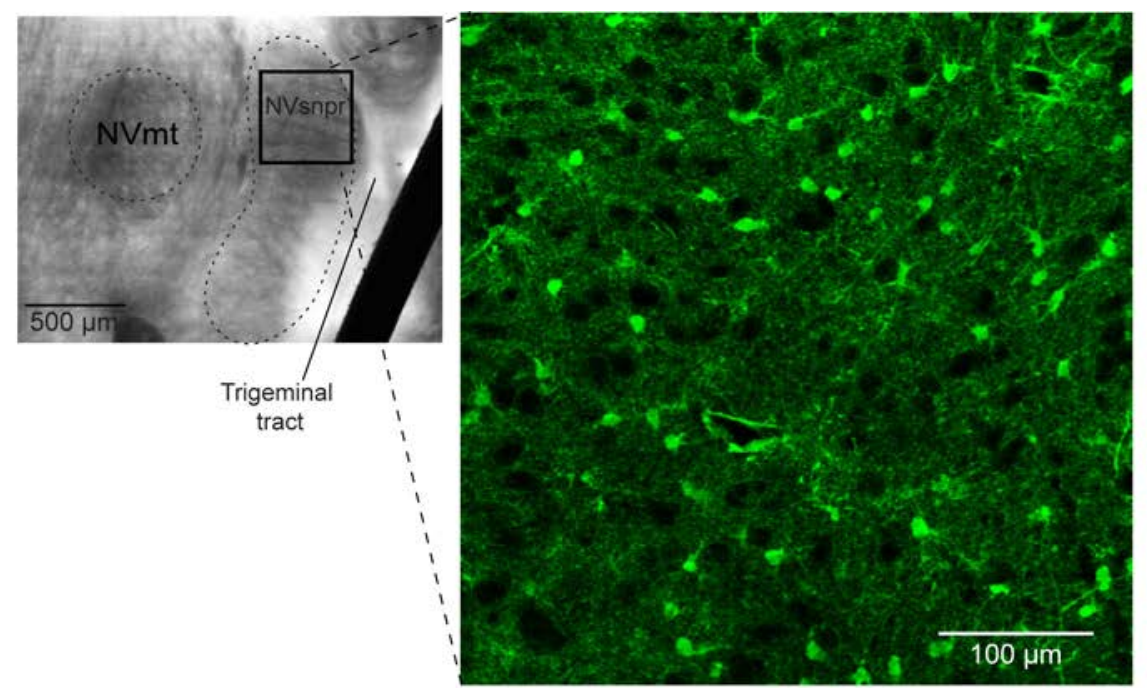

Supplementary Figure 5: Immunostaining of $\mathbf{S} 100 \beta$ in dorsal NVsnpr. The dorsal part of NVsnpr (box in the image on left) contains a large number of immunoreactive astrocytes when an antibody against $\mathrm{S} 100 \beta$ is used. 
Nature Neuroscience 18 : 844-854 / doi:10.1038/nn.4013

Control

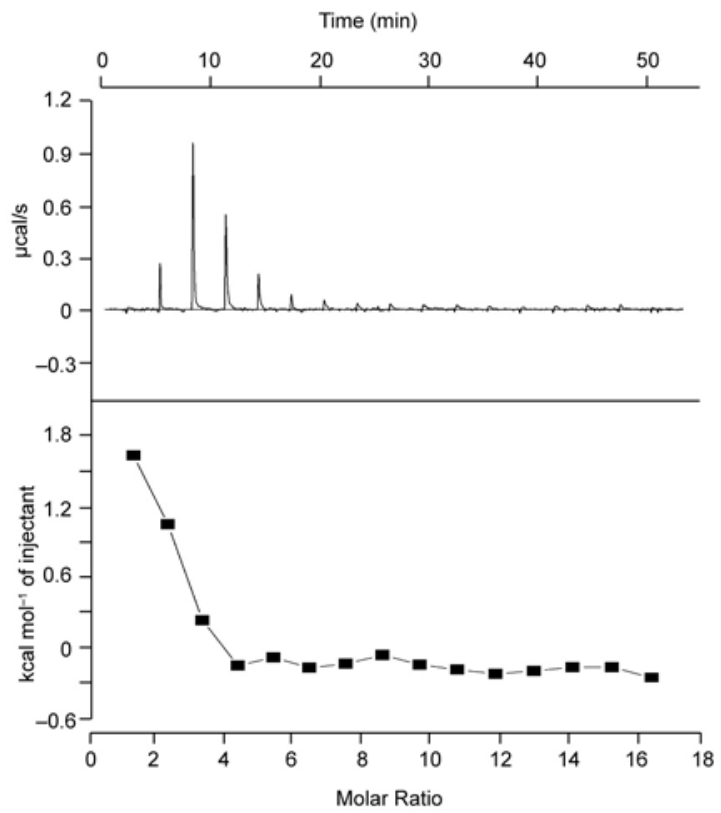

b

$+\mathrm{S} 100 \beta$ antibody

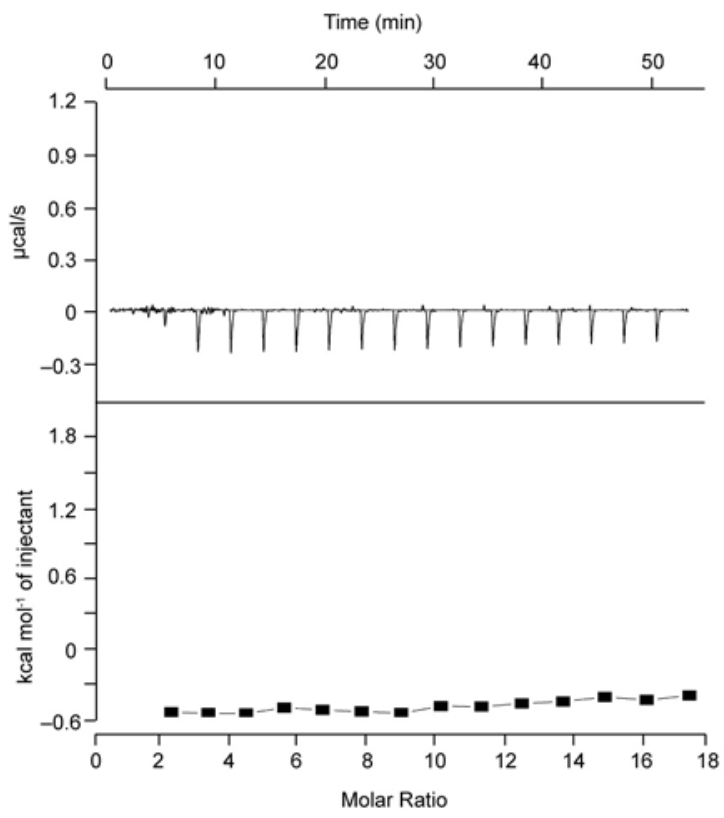

Supplementary Figure 6: Binding of $\mathrm{Ca}^{2+}$ to $\mathrm{S} 100 \beta$ is prevented in presence of an antibody. Isothermal titration calorimetry data for the titration of $\mathrm{S} 100 \beta$ with $\mathrm{Ca}^{2+}$ in the absence (a) or the presence (b) of an anti-S100 $\beta$ antibody. Top panel: raw thermogram of $\mathrm{S} 100 \beta$ titrated with $\mathrm{CaCl}_{2}$ at $20^{\circ} \mathrm{C}$. Bottom panel: Integrated heats of the raw data from the top panel. 

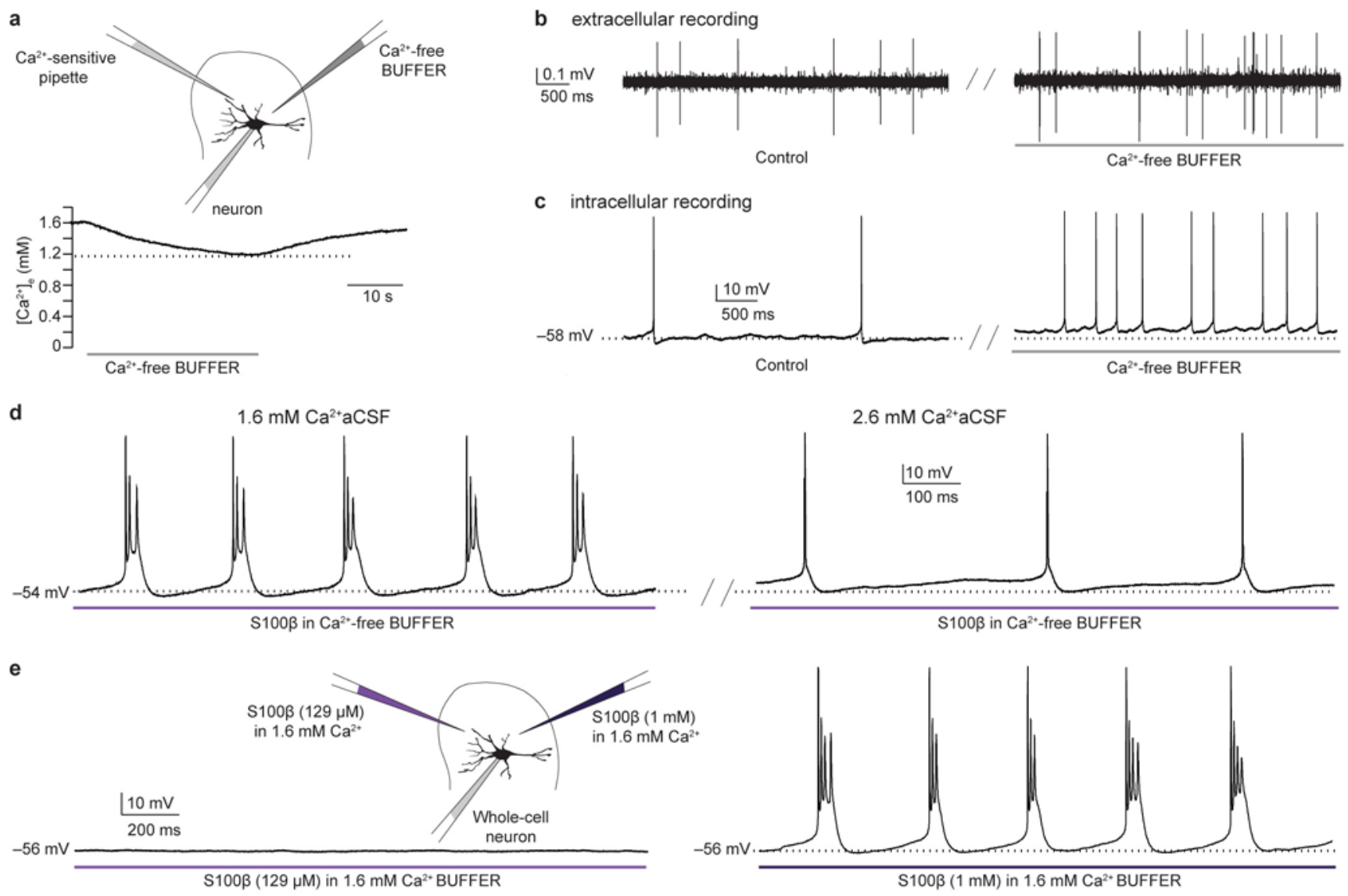

Supplementary Figure 7: Effects of $\mathrm{S} 100 \beta$ depend on its ability to reduce the extracellular calcium. (a) Local application of the Ca ${ }^{2+}$-free buffer used to dilute $S 100 \beta$ induces a small decrease of $\left[\mathrm{Ca}^{2+}\right]_{e}(n=6$ recording sites in 6 slices from 3 rats), but does not cause bursting in NVsnpr neurons, in neither the interface ((b) extracellular recording; right trace, $n=11$ cells in 11 slices from 6 rats) or the submerged configuration ((c) intracellular recording; right trace, $\mathrm{n}=3$ cells in 3 slices from 2 rats). (d) Local application of $\mathrm{S} 100 \beta$ diluted in the Ca ${ }^{2+}$-free buffer elicits neuronal bursting (left trace) in a cell from a preparation submerged in normal aCSF (with $1.6 \mathrm{mM} \mathrm{Ca2+}$ ), but not after raising the $\left[\mathrm{Ca}^{2+}\right]_{e}$ in the aCSF to $2.6 \mathrm{mM}$ ( $n=4$ cells in 4 slices from 3 rats). (e) Local application of S100 $\beta$ diluted in a buffer containing $1.6 \mathrm{mM} \mathrm{Ca}^{2+}$ can still elicit bursting, when its concentration is increased to $1 \mathrm{mM}$ (right trace ( $\mathrm{n}=10$ cells in 4 slices from 4 rats) to prevent its saturation, but not at the concentration of $129 \mu \mathrm{M}$; left trace ( $n=5$ cells in 3 slices from 3 rats). 
LOW LEVEL OF ACTIVITY

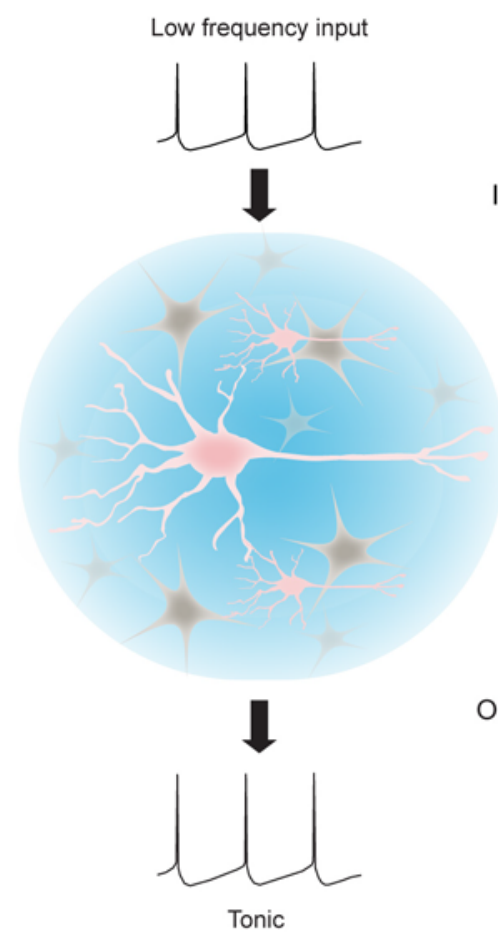

SENSORY RELAY MODE
HIGH LEVEL OF ACTIVITY

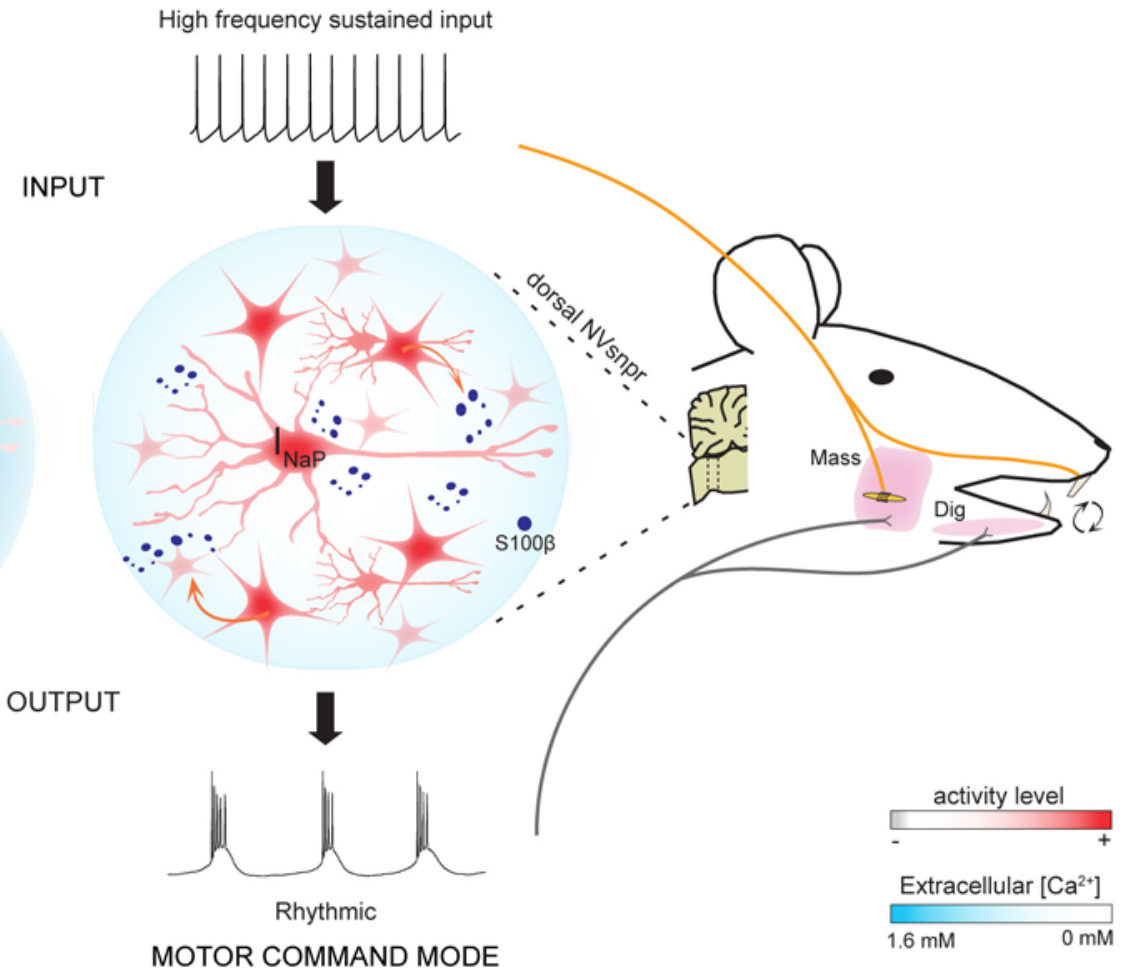

Supplementary Figure 8: Model of the sequence of events leading to rhythmogenesis. Left: Low sensory activity level are insufficient to activate astrocytes and lower $\left[\mathrm{Ca}^{2+}\right]_{\mathrm{e}}$, thus preventing activation of $\mathrm{I}_{\mathrm{NaP}}$ and neuronal bursting. In this condition, NVsnpr neurons work in a sensory relay mode with their tonic output faithfully relaying their tonic input. Right: With food intake and intraoral stimulation, sensory inputs from the periodontal ligament and the jaw muscle spindles increase their activity level and signal the need for rhythmic mastication. This increased activity activates astrocytes and leads to release of the $\mathrm{Ca}^{2+}$-binding protein $\mathrm{S} 100 \mathrm{\beta}$ and subsequent decrease of $\left[\mathrm{Ca}^{2+}\right]_{\mathrm{e}}$. This in turn will activate $\mathrm{I}_{\mathrm{NaP}}$ and elicit rhythmic bursting in NVsnpr neurons. The generated bursting frequency and pattern, reflecting the pattern of sensory inputs will then be transmitted to jaw closing and opening motoneuronal pools (masseter (mass) and digastric (dig), respectively). 